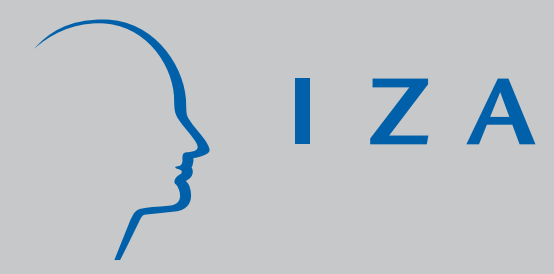

IZA DP No. 2699

Maternity Leave Legislation, Female Labor Supply, and the Family Wage Gap

Uta Schönberg

J ohannes Ludsteck

March 2007 


\title{
Maternity Leave Legislation, Female Labor Supply, and the Family Wage Gap
}

\author{
Uta Schönberg \\ University of Rochester \\ and IZA \\ Johannes Ludsteck
}

$I A B$, Nuremberg
Discussion Paper No. 2699
March 2007

\author{
IZA \\ P.O. Box 7240 \\ 53072 Bonn \\ Germany \\ Phone: +49-228-3894-0 \\ Fax: +49-228-3894-180 \\ E-mail: iza@iza.org
}

Any opinions expressed here are those of the author(s) and not those of the institute. Research disseminated by IZA may include views on policy, but the institute itself takes no institutional policy positions.

The Institute for the Study of Labor (IZA) in Bonn is a local and virtual international research center and a place of communication between science, politics and business. IZA is an independent nonprofit company supported by Deutsche Post World Net. The center is associated with the University of Bonn and offers a stimulating research environment through its research networks, research support, and visitors and doctoral programs. IZA engages in (i) original and internationally competitive research in all fields of labor economics, (ii) development of policy concepts, and (iii) dissemination of research results and concepts to the interested public.

IZA Discussion Papers often represent preliminary work and are circulated to encourage discussion. Citation of such a paper should account for its provisional character. A revised version may be available directly from the author. 


\section{ABSTRACT}

\section{Maternity Leave Legislation, Female Labor Supply, and the Family Wage Gap*}

This paper analyzes the impact of expansions in leave coverage on mothers' labor market outcomes after childbirth. The focus is on Germany, a country that underwent several changes in maternity leave legislation since the late 70 s. We identify the causal impact of an expansion in maternity leave by comparing labor market outcomes of women who gave birth shortly (i.e. one month) before and after a change in maternity leave legislation. There is strong evidence that each expansion induced women to delay their return to work. Despite this strong short-term effect, the expansions had little impact on women's labor supply in the long-run. The expansion from 2 to 6 months reduced women's wages, even 8 years after childbirth. This effect is mostly explained by the delay in the return to work. The delay in the return to work caused by the expansions in leave from 6 to 10 months and 18 to 36 months also lowered wages. However, this negative effect is offset by a positive selection effect, resulting in a zero or even positive overall effect.

JEL Classification: J16, J18, J24

Keywords: gender, human capital, parental leave

Corresponding author:

Uta Schönberg

Department of Economics

University of Rochester

Rochester, NY 14627

USA

E-mail: utas@troi.cc.rochester.edu

\footnotetext{
* We thank Mark Bils, Gordon Dahl, Christian Dustmann, Ronni Pavan, and participants at SOLE meetings in San Francisco, the World Congress of the Econometric Society in Vienna, the IZA/SOLE Transatlantic Meetings of Labor Economists, and seminar participants in Chicago GSB, the Rand Corporation, and Rochester for helpful comments and suggestions. All remaining errors are our own.
} 


\section{Introduction}

At present, almost every country has provisions for maternity leave allowing mothers to leave their workplace for a limited time around childbirth, and giving them the right to return to their previous employer afterwards. However, these provisions vary widely across countries. Since the introduction of the Family and Medical Leave Act (FMLA) in 1993, women in the US are entitled to 12 weeks of (unpaid) parental leave. The country with the longest leave provision is Germany where women are currently eligible for 3 years of (partially paid) leave. There is a recent trend towards an expansion in leave coverage. For instance, Canada increased paid family leave from about 25 weeks to 50 weeks in 2000. In 2003, California approved a policy that entitles women to up to 6 months of paid leave. Other US states, such as Massachusetts and New Jersey, are considering implementing similar policies. Other countries that have recently extended their leave coverage include the UK (2003, 2007) and Denmark (2002).

Despite the widespread prevalence of parental leave policies, their economic impact is not fully understood. Proponents argue that by encouraging employment continuity, parental leave policies promote gender equality and increase women's earnings. Proponents further argue that leave policies improve of the health of the mother and the welfare of the child. Opponents counter that by restricting voluntary agreements between firms and workers, leave policies worsen women's position in the labor market.

This paper investigates the impact of the expansions in maternity leave coverage on women's labor market outcomes after childbirth. Our analysis focuses on Germany - a country that has experienced a series of changes in maternity leave legislation since the late 70 s. The first change occurred in 1979 when maternity leave was raised from 2 to 6 months, a reform is comparable to the 2003 expansion in leave coverage in California. The main motivation behind this reform 
was the health of the mother; it was argued that the female body takes longer than two months to fully recover from pregnancy. In 1986, maternity leave was further expanded to 10 months. This reform shares some similarities to the Canadian and Danish reforms implemented in 2000 and 2002, respectively. Since 1992, women are entitled to 3 years of job-protected leave. The main motivation behind these reforms was the welfare of the child; it was argued that the early years are the most important ones in a child's life, and the reforms were explicitly aimed at encouraging mothers to spend more time with their child after childbirth.

This paper improves on much of the existing literature on the economic impact of maternity leave legislation ${ }^{1}$ by evaluating a series of policy changes, as opposed to a single, specific reform. This is important because the impact of leave coverage on mothers' labor market outcomes may be non-linear: An expansion in leave from 2 to 6 months may affect labor market outcomes differently from an expansion in leave from 18 to 36 months.

Much of the existing literature is plagued by the difficulty of isolating the causal impact of the policy change from aggregate time trends. We overcome this problem by comparing labor market outcomes of women who give birth shortly before or after a change in legislation. For instance, for the first policy reform, we compare women who give birth in April 1979 and are entitled to 2 months of leave with women who give birth in May 1979 and are entitled to 6 months of leave. For such an estimation strategy to work well, we require a large data set. Our data comes from social security records for the years 1975 to 2001, and allows us to construct the complete work history of every woman covered by the social security system.

We further improve on the existing literature by considering several labor market outcomes at the same time - most importantly labor force participation and wages - as well as by focusing

\footnotetext{
${ }^{1}$ We summarize this literature in Section 2.1.
} 
on the long-term impacts of the leave expansions, up to 8 years after childbirth.

Our main results can be summarized as follows. Each expansion in maternity leave induced women to delay their return to work. The delay is strongest for the increase in job-protected leave from 2 to 6 months in 1979, and weakest for the increase from 18 to 36 months in 1992. Hence, the reforms succeeded in increasing the time mothers spend with their children after childbirth. However, whether this indeed improves the health of the mother or the welfare of the child remains an open question.

Despite this strong short-term impact on labor supply, the expansions had little impact on mothers' labor force participation rates in the long run. This suggests that the expansions in leave coverage failed at promoting employment continuity of mothers. It further suggests that time away from work has only a small causal impact on future labor market attachment. The detrimental effect that time away form work may have on future employment is, however, at the heart of the current debate on the design of social assistance and welfare programs.

The delay in the return to work implies that mothers lose more and accumulate less human capital after childbirth. Did the expansions in leave coverage therefore lower mothers' postbirth wages? We find this to be the case for the expansion in leave from 2 to 6 months. The delay in the return to work caused by the expansions in leave coverage from 6 to 10 and 18 to 36 months also reduced wages. However, women who make full use of the maternity leave legislation and return to work exactly when leave expires are negatively selected in terms of pre- and post-birth wages, and the more so the longer the leave period. For the expansions in leave from 6 to 10 and 18 to 36 months, this selection effect works in the opposite direction as the human capital effect, resulting in a zero or even a positive overall wage effect. These results point to the importance of career interruptions due to childbirth in explaining the family 
and gender wage gap. They also cast some doubt on whether expansions in leave coverage are successful at promoting gender equality.

Our final finding points to the problem of enforcing maternity leave rules. Mothers are only protected from dismissal during the leave period. Once the leave period expires, the regular employment protection rules apply, and it becomes possible for firms to lay off women. Hence, firms may avoid the maternity leave legislation by laying off women after the leave period. We find evidence that is compatible with this: Up to $7 \%$ of women return to work exactly when leave expires, but become unemployed only one or two months later.

The structure of the paper is as follows. We begin with a brief literature review (Section 2.1). Section 2.2 describes the main features of maternity leave legislation in Germany. We then outline our empirical strategy in Section 3, and describe the data in Section 4. Section 5 reports results. Section 6 concludes with a discussion of the implications of our findings.

\section{Background}

\subsection{Previous research}

We begin with a brief overview of the literature on maternity leave legislation ${ }^{2}$. Several studies indicate that an expansion in job-protected leave causes women to delay their return to work. For the US, Baum (2003a) provides some evidence that state-wide maternity leave policies

\footnotetext{
${ }^{2}$ In an important paper, Ruhm (1998) analyzes labor market consequences of rights to paternity leave for nine European countries over the 1969 through 1993 period (see also Ruhm and Teague 1997). This study is not directly comparable with ours, as it is based on aggregate data from the OECD, and makes no distinction between women with and without children. Ruhm (1998) finds that maternity leave legislation rises women's employment ratios, but has no impact on their earnings. The study leaves open the channels through which maternity leave legislation operates. Do more generous maternity leave mandates increase the employment ratio because childless mothers are more likely to work in order to qualify for maternity benefits? Or do more generous leave mandates increase the labor supply of women with children?
} 
together with the Family and Medical Leave Act (FMLA) of 1993 induced women to postpone their return to work. In line with this result, Berger and Waldfogel (2004) find that women in jobs that provided leave coverage are more likely to take leave of up to 12 weeks, but return more quickly after 12 weeks. For Canada, Baker and Milligan (2005) conclude that short mandates have little impact on a mother's labor supply - probably because they duplicate private arrangements. Longer mandates, in contrast, increase the time women spend at home with their infants. Hanratty and Trzcinski (2005) focus on the impact of the expansion of paid maternity benefits from 25 to 50 weeks in Canada in 2000. They also report that women waited longer after the expansion. Finally, Lalive and Zweimüller (2005) find that the expansion in job-protected leave from one to two years in Austria strongly reduced the probability that women return to work within one year of childbirth.

In contrast, evidence on the long-term effects of maternity leave legislation on female labor supply past childbirth is scarce and mixed. For the US, Klerman and Leibowitz (1997) do not find any significant impact of maternity leave mandates on employment. Hanratty and Trzcinski (2005) also argue that the 2000 reform in maternity leave legislation in Canada had little impact on the employment ratios one year after childbirth. In contrast, Ondrich et al. (2003a) provide some suggestive evidence that the expansions in leave coverage in Germany reduced employment of mothers. Likewise, Lalive and Zweimüller $(2005,2006)$ find that the Austrian reform lowered the proportion of women who have not returned to the labor market within 8 years of childbirth by 8 percentage points. However, Lalive and Zweimüller (2005) evaluate a reform that provided a strong financial incentive for women to become pregnant with a second child within two years, prior to the expiration of the leave period. This incentive is weaker in the German legislation as well as in the legislation of many other countries with 
long leave mandates.

Only few papers analyze the impact of maternity leave mandates on wages for returning mothers. Both Baum (2003b) and Waldfogel (1999) find that in the US, the FMLA had no significant effect on women's wages. For Germany, Ondrich et al. (2003b) report that the increases in maternity leave led to lower wage growth for returning mothers. It is important to bear in mind, however, that these studies are based on small sample sizes, and because of the absence of a good control group, may not identify the causal impact of the law. Waldfogel $(1997,1998)$ and Waldfogel et al. (1999) examine the effect of maternity leave coverage provided by employers, as opposed to coverage mandated by the government. They find that women who are covered by maternity leave and returned to work after childbirth earned wages up to $20 \%$ higher than those who are not. However, these large gains may reflect a selection of women with a high earnings potential into jobs that provide maternity leave coverage, rather than a causal relationship. In line with this argument, Hashimoto et al. (2004) show that the impact of maternity leave coverage on wages is small and short-lived once selection into jobs that provide coverage is appropriately controlled for. Lalive and Zweimüller (2006) also find that the expansion in leave coverage from 1 to 2 years in Austria had little impact on women's subsequent earnings.

This paper improves and extends this literature in several ways. First, we isolate the causal impact of the expansions from aggregate time trends by comparing labor market outcomes of women who give birth shortly before or after the policy change. Second, we evaluate a series of policy changes as opposed to a single, specific reform, allowing us to detect possible nonlinearities in the impact of maternity leave legislation on labor market outcomes. A further advantage of our study is the large sample size of our data, allowing us to estimate the impact 
of expansions in leave coverage on wages and employment more precisely.

Next, we describe in detail the expansions in leave coverage that have taken place in Germany since the late 70 s.

\subsection{Maternity Leave Legislation in Germany}

The US introduced the first federal, government-mandated parental leave policy, the Family and Medical Leave Act (FMLA) in 1993. The FMLA requires companies with more than 50 employees to provide 12 weeks of unpaid parental leave. In Germany, a similar coverage has been available to mothers since 1952. Since 1968, mothers are entitled to paid maternity leave 6 weeks before and 8 weeks after childbirth. Firms are not allowed to dismiss women during this period. It is important to stress that mothers have the right to return to a job that is comparable to the job they held before childbirth; firms are not required to keep the same job available. Payment during the leave period is equivalent to mothers' average earnings during the last three months prior to childbirth. Costs are shared between the public health insurance, the federal government, and the employer. The federal government contributes 200 Euros as a one time payment per child. The health insurance pays around 12.50 Euros per calender day, or about 375 Euros per month. The additional costs are borne by the employer ${ }^{3}$.

Since the late 70s, there have been several expansions in leave coverage. Figure 1 provides a visual overview of the reforms. The first reform took place in May 1979. This reform is comparable to the California expansion in leave coverage in 2003. It raised the job-protected maternity leave period from 2 to 6 months. It further turned the entitlement of leave 6 weeks before and 8 weeks after childbirth into a prohibition of work. The main motivation behind

\footnotetext{
${ }^{3}$ Firms with less than 20 employees were exempt from paying maternity benefits. In this case, the additional costs are borne by the federal government.
} 
this reform was the health of the mother; it was argued that female body takes longer than two months to fully recover from the pregnancy. Payment during this period remained unchanged from mothers' earnings prior to childbirth. Payment between the 3rd and 6th month following childbirth was equivalent to sick pay, and up to 375 Euros per month ${ }^{4}$. This corresponds to about one third of women's average pre-birth earnings. Note that this sharp reduction in maternity benefits allows us to disentangle the impact of these benefits from the impact of job protection on the mother's labor supply. Maternity benefits from the 3rd month onwards were paid by the federal government. Only women who were employed before childbirth were entitled to maternity benefits.

The reforms implemented during the mid-80s and early 90s shifted the focus from health of mother to welfare of the child. It was argued that the early years are the most important ones in a child's life, and the reforms were explicitly aimed at encouraging mothers (and possibly fathers) to spend more time with their child after childbirth. The 1986 reform increased the jobprotection period from 6 to 10 months and announced a further increase to 12 months starting in January 1988. This reform thus shares some similarities to the Canadian and Danish reform implemented in 2000 and 2002, respectively. An important component of the 1986 reform was that all mothers - regardless of their employment status prior to childbirth - became eligible for maternity benefits. During the 6 weeks prior to and 8 weeks following childbirth, the maternity benefit remained unchanged from mothers' pre-birth earnings (or 300 Euro if the mother was not employed before childbirth). From the third to the sixth month after childbirth, maternity benefits are equal to 300 Euros, independently of the mother's (or the father's) income prior to childbirth. This corresponds to about $20 \%$ of women's average pre-birth earnings. From

\footnotetext{
${ }^{4}$ It was reduced to $510 \mathrm{DM}(\approx 255$ Euros $)$ per child and month in 1984.
} 
the seventh month onwards, maternity benefits are means-tested and depend on the annual net family income two years before childbirth. The majority of women receive benefits longer than 6 months. In 1986, this proportion was $83.6 \%$ (Engstler and Menning (2003), Bundesministerium für Familie, Senioren, Frauen und Jugend $(2000))^{5}$. Benefits from the 3rd month onwards are paid by the federal government. A further component of the reform is that fathers became eligible for leave taking. However, the proportion of fathers taking parental leave is very small; in 2001 it was $1.6 \%$ (Engstler and Menning (2003)).

In July 1989 and July 1990, the job-protected leave period was further raised to 15 and 18 months, respectively. The final policy reform took place in January 1992 when job-protected leave was raised from 18 to 36 months. This reform kept the maximum duration during which women are entitled to maternity benefits at 18 months. In January 1993, this period was extended to 24 months $^{6}$. Note that these two policy reforms provide a further opportunity to isolate the impact of maternity benefits from the impact of job-protection on the mother's return decision.

Our empirical analysis focuses on the three major policy reforms: the increase in jobprotected leave from 2 to 6 months in 1979, the increase from 6 to 10 months 1986 , and the increase from 18 to 36 months 1992.

\footnotetext{
${ }^{5}$ Some West-German states pay maternity benefits in addition to the federal benefits. The West-German states who pay additional maternity benefits are Bayern, Baden-Württemberg, and Rheinland-Pfalz. See Rosenschon (2001) for details.

${ }^{6}$ If a woman has a second child within the period during which maternity benefits are paid (i.e. 18 months since July 1989 and 24 months since January 1993), she receives the full maternity benefits for both children - just as she would if she had the second child after the expiration of the benefit period. If the mother has a second child within the job-protection period (i.e. 3 years since January 1992), her employer has to keep her job available for another 3 years starting from the birthday of her second child.
} 


\section{$3 \quad$ Estimation Strategy}

We identify the causal effect of maternity leave legislation on labor market outcomes by comparing women who gave birth just before and just after the policy reform. Consider for instance the increase in job-protected leave from 2 to 6 months that took place in May 1979. Here, our estimation strategy amounts to comparing women who gave birth in April and were subject to 2 months of job-protected leave with women who gave birth in May and were subject to 6 months of leave. Our identifying assumption is that it is random whether a woman gives birth in April or in May. A similar strategy was used by Lalive and Zweimüller (2005) to evaluate the impact of an Austrian policy reform on fertility, and by Ekberg et al. (2005) to analyze the impact of Sweden's 'daddy month reform' on the labor supply of fathers. Next, we discuss possible problems with this strategy.

Problems One reason why the identifying assumption might be violated is that there are inherent differences between births in different months of the year. Such differences could arise because of seasonalities or because of data peculiarities ${ }^{7}$. This problem can be dealt with by using mothers who give birth in the same months, but in a year in which there was no change in maternity leave legislation as a control group.

Second, our identification strategy would not be valid if women timed the birth of their child as a response to the change in maternity leave legislation. We believe that this is unlikely, at least for the reforms that took place in 1979,1986 , and $1992^{8}$. This is because women could not anticipate these reforms. We searched three leading German newspapers ${ }^{9}$ for articles

\footnotetext{
${ }^{7}$ In our data, February births tend to be different from births in other months. This is probably a consequence of our restriction that leave spells starting the first of a month are dropped - see Section 4 for more details.

${ }^{8}$ The 1988 reform that extended job-protected leave from 10 to 12 months was already decided in 1986 . The 1990 reform that extended job-protected leave from 15 to 18 months was already decided in 1989.

${ }^{9}$ The search was conducted in the following newspapers: Süddeutsche Zeitung, Frankfurter Allgemeine, and
} 
about the reform. The first articles typically appear two to three months before the reform was finally implemented. By that time, children born around the change in the law would already have been conceived. It is true that women still have some opportunities to time the birth of their child through induced births or cesarean $\operatorname{cuts}^{10}$. However, this allows women to bring the birth date forward - whereas in our case women presumably would like to postpone childbirth in order to be eligible for the more generous leave policy. It is also worth pointing out that throughout the time period of consideration, cesarean cuts were relatively rare and predominantly occurred for medical reasons.

Third, even if it is random whether a woman gives birth shortly before or shortly after the policy reform, the probability that she takes maternity leave may be influenced by the reform and therefore not exogenous. To check whether this is a problem, we first compare the pre-birth characteristics of those mothers who give birth shortly before the legislated maternity leave extension to those who give birth shortly after. Table 1 reports results for the three major reforms: the increase in job-protected leave from 2 to 6 months, from 6 to 10 months, and from 18 to 36 months. The differences are small and not statistically significant. The same holds when comparing women who give birth three months before to those who give birth three months after the policy reform. In contrast, differences between women who give birth one year before and those who give birth one year after a change in maternity leave legislation are substantial and consistently statistically significant.

We also use data from the German Pension Register to check whether there is a discontinuity in the fraction of women taking maternity leave when job-protected leave is extended; see Die Zeit.

${ }^{10}$ Dickert-Conlin and Chandra (1999) provide evidence that women time childbirth as a response to financial incentives. They find that the probability that a child is born in the last week of December rather than the first week of January is positively correlated with tax benefits in the US. 
Section 4 for a description of this data set. Since the data starts in 1986 only, we are not able to evaluate the extensions in job-protected leave from 2 to 6 months and 6 to 10 months. Results can be found in Appendix B. We find no significant increase or drop in the incidence of leave taking when maternity leave was expanded, although the sample size may be too small to draw definite conclusions.

Next, we describe the data used in the empirical analysis.

\section{Data}

Our data comes from Social Security Records (BLH - Beschäftigten-Leistungsempfänger-Historik). The data allows us to construct the complete work history - including time spent in unemployment and on leave of absence - of every man and woman covered by the social security system. Not included in the data are civil servants (including teachers) and the self employed. So-called marginal jobs that are exempt from social security contributions are reported in the data only after 1999. These include jobs with at most 15 hours per week or temporary jobs that last no longer than 6 weeks. Altogether, the data represents about $80 \%$ of the German work force. From this database, we select all West-German women who go on maternity leave between 1976 and 1993 and are between 16 and 45 years of age. Further details on the sample selection as well as variable definitions can be found in Appendix A.1.

An important advantage of our data is its large sample size; in our final sample, there are up to 25,000 women who go on maternity leave each month. This is crucial for our estimation strategy which consists of comparing women who give birth just before and just after a change in maternity leave legislation. A further advantage is that, due to the administrative nature of 
the data, employment and wages are measured very precisely.

However, our data also have two main shortcomings. First, they do not contain direct information on children. We only observe whether and when a woman goes on leave. We thus have to infer the birth month of the child from the month the mother goes on leave. This is likely to lead to some measurement error. Second, not all leave taking may be maternity in nature. Alternative reasons include military service, illness, disability, and early retirement. Our sample may thus include some women who are on leave but have not given birth.

We use an additional data source, the German Pension Register, to address these problems. The German Pension Register is a 1\% random sample drawn from our data base, supplemented with precise information on when a woman gave birth. The data is principally available from 1975 to 1995. However, reliable fertility data exists only from 1986 onwards.

How Many Leave Spells Are due to Childbirth? We first use the German pension register to check how many leave spells are due to reasons other than maternity leave, such as retirement, illness, etc. Exact variable definitions as well as details on the selection criteria can be found in Appendix A.2.

The first column of Table 2 shows the proportion of leave spells due to childbirth in our data, separately by the month the spell started. In total, about $14 \%$ of the leave spells are not due to childbirth. In January, however, the fraction of 'wrong' leave spells increases to $36 \%$. It turns out that most of these 'wrong' leave spells start at the first of the month. Column 2 of Table 2 displays the proportion of true leave spells after dropping spells that start at the first of a month. This reduces the total fraction of wrong leave spells to about $9 \%$. More importantly, it is now roughly the same across months. We therefore discard all leave spells that begin at 
the first of the month.

Inevitably, by doing so we lose correct leave spells. After we impose this restriction, there are less recorded births in February (leave spells that start at the first of January are recorded as February births) than in any other month in our main data. February births differ with respect to observable pre-birth characteristics as well as post-birth labor market outcomes. In order to make sure that our results are not driven by this data peculiarity, we do not include February births in the emprical analysis. Results are similar if we include February births and use as a control group February births from a year in which no change in maternity leave legislation occurred.

The Month a Mother Goes on Leave and the Month She Gives Birth Next, we use the German Pension Register to analyze the relationship between the month a woman gives birth and the month she goes on leave. Details on the selection criteria as well as exact variable definitions can be found in Appendix A.2.

Since women are (since May 1979) prohibited from working 6 weeks before birth, we approximate the birthday of the child as 6 weeks after the mother went on leave. Table 3 shows that with this definition, the child's birth month is correctly specified in about $70 \%$ of the cases. In about $12 \%$ of the cases, we either over- or underestimate the true birth month by one month. The second panel of Table 3 reveals that the distribution is somewhat asymmetric; there are more 'too early' than 'too late' childbirths (13.09\% versus $17.11 \%)$. This is not surprising, as women who are sick during pregnancy are likely to go on leave earlier.

How Does Measurement Error Affect Our Estimates? How do these two types of measurement error affect our estimates? Consider first the first type of measurement error, i.e. 
that not all leave spells are maternity in nature (Table 2). We used the Pension data to check whether the incidence of a wrong leave spell is correlated with the month or year a woman gives birth. This does not appear to be the case. Moreover, labor market outcomes of women with 'wrong' leave spells do not vary with the year or month the spell started. This implies that our estimates are biased towards zero ${ }^{11}$. Since we know the fraction of correct leave spells, in principle we could correct for this type of measurement error by dividing by the fraction of correct leave spells. We decided not to do so because of the relatively small fraction of incorrect leave spells.

Next, consider the second type of measurement error, i.e. the incorrect measurement in the child's birth month (Table 3). This type of measurement error implies that some women whom we record giving birth just before a change in maternity leave legislation have in fact given birth after the change, and vice versa. According to the Pension data, the probability of a mis-recorded birth does not vary with the month or the year a mother gives birth. This implies once again that our estimates are biased towards zero. We deal with this type of problem by comparing labor market outcomes of women who give birth 2 (or 3, 4, etc) months before to women who give birth $2(3,4$, etc.) months after a change in maternity leave legislation; the mis-classification of the true birth month - and thus the bias due to measurement error - should be lower for these women. We also provide estimates that correct for measurement error by dividing the observed difference in labor market outcomes one month before and one

\footnotetext{
${ }^{11}$ To see this, let $p_{j}$ denote the proportion of correct leave spells; $Y_{j}^{M}$ denotes labor market outcomes of women who give birth in month $j$ under legislation $M$; and $I_{j}$ denotes labor market outcomes of women who have not given birth and whose leave spell starts in month $j$. Since the fraction of incorrect leave spells does not vary by the year or month the leave started, the observed difference between labor market outcomes of women whose leave started one month before or after the change in law equals

$$
\bar{Y}_{-1}^{M_{1}}-\bar{Y}_{+1}^{M_{2}}=\left(p_{-1} Y_{-1}^{M_{1}}+\left(1-p_{-1}\right) I_{-1}\right)-\left(p_{+1} Y_{+1}^{M_{2}}+\left(1-p_{+1}\right) I_{+1}\right) .
$$

According to our data, $p_{-1}=p_{+1}$, and $I_{-1}=I_{+1}$. Hence, $\bar{Y}_{-1}^{M_{1}}-\bar{Y}_{+1}^{M_{2}}=p\left(Y_{-1}^{M_{1}}-Y_{+1}^{M_{2}}\right)$.
} 
month after the change in law by the fraction of births that are correctly recorded (roughly $70 \%$, according to Table 3$)^{12}$.

Variable Description Our main variables are defined as follows. Due to the measurement error in the birth month, a woman is considered to be working $t$ months after childbirth if she is working in month $t-1, t$, or $t+1$ after childbirth. Similarly, a woman is considered to have returned to work by month $t$ after childbirth if she has returned by month $t+1$. We require women to return to work for at least two consecutive months. Full-time work refers to work between 20 and 30 hours per week. Marginal jobs with less than 20 hours per week are excluded from the analysis. Our wage measure is the daily wage, averaged over the days a woman was working for a single employer during the year. Hence, a lower wage may be either due to a lower hourly wage rate, or due to fewer hours worked per day. Pre-birth characteristics are measured 9 months prior to childbirth. Further details can be found in Appendix A.1.

When focusing on the long-term consequences of maternity leave legislation, we use labor outcomes measured 12, 24, 36 etc. months after childbirth for the 1979 policy reform, but 18, 30, 42 etc. months after childbirth for the 1986 and 1992 policy reforms. We do this to make sure that the wage or employment spell of women who give birth before or after the reform refer to the same calendar year; see Appendix A.1 for a further explanation.

\footnotetext{
${ }^{12}$ To see this, let $Y_{j}^{M}$ denote labor market outcomes of women who give birth in month $j$ under maternity leave legislation $M ; P_{0}$ denotes the proportion of births that are correctly recorded; $P_{-1}$ denotes the proportion of births that are recorded one month too late (e.g. the true birth month is March, but we record April); and $P_{+1}$ denotes the proportion of births that are recorded to early. These proportion are not indexed by the birth month because according to our data there is no evidence for a correlation between the probability of a correctly recorded birth and the birth month. The observed difference between labor market outcomes of women whom we record to give birth one month before or after a change in legislation equals

$$
\begin{aligned}
\bar{Y}_{-1}^{M_{1}}-\bar{Y}_{+1}^{M_{2}}= & \left(P_{-1} Y_{-2}^{M_{1}}+P_{0} Y_{-1}^{M_{1}}+P_{+1} Y_{+1}^{M_{2}}\right) \\
& -\left(P_{-1} Y_{-2}^{M_{1}}+P_{0} Y_{-1}^{M_{1}}+P_{+1} Y_{+2}^{M_{2}}\right) .
\end{aligned}
$$

Under the assumptions that $Y_{-2}^{M_{1}}=Y_{-1}^{M_{1}}$, and $Y_{+1}^{M_{2}}=Y_{+2}^{M_{2}}$, this difference equals $P_{0}\left(Y_{-1}^{M_{1}}-Y_{+1}^{M_{2}}\right)$.
} 
Overview of Sample Period and Data Table 4 provides an overview of our sample period and data. Panel A focuses on the fertility rate as well as the share of women who take maternity leave. Column 3 shows the fertility rate, i.e. the average number of children of women who are between 15 and 45 years old, between 1977 and 1993. While there are sizable fluctuations over this period, there appears to be no long-run trend.

Column 4 displays the number of all births (excluding births where both parents are not German citizens) in West Germany; and Column 5 lists the number of women who go on maternity leave in our data. The ratio between the two numbers reported in Column 6 is a proxy for the fraction of mothers who take maternity leave. There appears to be a clear upward trend in leave taking; the number of observations in our data as a percentage of the total number of births increased from $31.74 \%$ in 1977 to $44.60 \%$ in 1992.

Column 7 likely underestimates leave taking because our data excludes up to $20 \%$ of the German work force. Using data from the German Pension Register, Column 7 provides an alternative and arguably more reliable estimate of leave taking from 1986 to 1993 . This data source reveals an almost 10 percentage point higher incidence of leave taking. Column 8 restricts the sample to women who were employed 9 months before giving birth. Among these women, leave taking is very common, as about $85 \%$ go on maternity leave.

Panel B focuses on how characteristics of mothers have changed throughout the sample period. In our sample, there are less university graduates than in the economy as a whole. This is because university graduates are less likely to have children and because one of the most popular occupation among female university graduates - teacher - is excluded in our data. In line with the general skill upgrading in the economy, the proportion of mothers with an apprenticeship and university degree substantially increased between 1976 and 1992 (Columns 
4 and 5). The average age at childbirth rose by 3 years from 26.3 in 1978 to 29.3 in 1992 , a trend that has also been observed in other developed countries. Finally, average daily wages increased by more than 30\%, despite the fact that part-time work before childbirth has become increasingly common.

The next section reports results.

\section{Results}

We begin with the impact of maternity leave legislation on a woman's labor supply (Section 5.1). We then turn to its impact on wages (Section 5.2). Unless otherwise noted, results do not condition on observable pre-birth characteristics. Our results are very similar when we do so.

\subsection{Maternity Leave and Labor Supply}

Women's Decision to Return to Work To get an idea how the maternity leave policy affects a woman's decision when to return to work, Figure 2 plots the proportion of women who return to work $t$ months after their child was born separately for the eight different policy regimes. Four characteristics stand out. First, a large fraction of mothers returns exactly when maternity leave expires. Second, this fraction is lower for more generous leave policies. For instance, in the late 70 s when women were entitled to 2 months of job-protected leave, $25 \%$ of women returned to work exactly two months after childbirth. In 1992, when women were entitled to 3 years of job-protected leave, $6 \%$ returned to work exactly 3 years after childbirth. Third, the fraction of women who return to work either in the month before or after maternity leave expires is higher than in other months. This is expected since often we over- 
or underestimate the birth month by one month (see Table 3). Fourth, we observe a higher fraction of women returning to the labor market when maternity benefits are reduced or expire (i.e. after 2, 6, 18 or 24 months), suggesting that women care not only about a job guarantee, but about maternity benefits as well. We discuss the impact of job protection and maternity benefits on a mother's labor supply in more detail below.

Next, we explore the return decision of women who give birth around a change in maternity leave legislation. Figures $3 \mathrm{a}$ and $3 \mathrm{~b}$ display the proportion of women who return to the labor market within 2 to 18 months after birth, for women who give birth between March 1976 and December 1993. The vertical lines indicate a change in maternity leave legislation. The figures reveal that the fraction of women who returned to work by month $T$ after childbirth sharply drops exactly when protected leave is raised from $T$ to $T^{\prime}$ months. For instance, the fraction of women who has returned to the labor market within 2 months of childbirth is $34 \%$ in March 1979, but only $9 \%$ in June 1979. In line with Figure 2, the drop is smaller for the later extensions.

The bold columns ((2), (6) and (18)) in Table 5 report several estimates for the delay in the return to work for the three major changes in maternity leave legislation (i.e. 2 versus 6 months, 6 versus 10 months, and 18 versus 36 months). We begin by comparing women who give birth one month before or after the change in law. We then display estimates that correct for measurement error in the recorded birth (see Section 4$)^{13}$. The third row compares women who give birth 2 or 3 months before and after the change in law ${ }^{14}$. In order to make sure that our results are not driven by inherent differences between mothers giving birth in different

\footnotetext{
${ }^{13}$ This estimate is obtained by dividing the original estimate by 0.69 , the fraction of births for which the birth month is correctly measured.

${ }^{14}$ For the reasons described in Section 4, we exclude February births from our analysis. Results are similar if we include February births, and use February births in a year in which there was no change in maternity leave legislation as a control group.
} 
months during the year, we finally report 'difference-in-difference estimates', using mothers who give birth in a year in which there was no change in maternity leave legislation as a control group. Once we correct for measurement error, all estimates give similar results. The first reform reduced the probability of returning to work within 2 months of childbirth by about 30 percentage points. The second reform caused $25-26 \%$ of women to delay their return to work, compared to about $7-8 \%$ of the third reform.

Does a more generous leave policy eventually bring more or less women back to work? The scale in Figures 3a and 3b is too coarse to reveal the long-term impact of the policy reforms. Figure 4 restricts the sample to women who give birth one year before or after a policy reform, and plots on a finer scale the fraction of women who have returned to work. The figure also plots the predicted fraction, obtained from a linear regression that uses monthly data and controls for a linear time trend and a discontinuous jump when the law was changed $(\mathrm{N}=24)$. The estimate for the discontinuous jump is reported as well. Panel A focuses on the expansion from 2 to 6 months, Panel $\mathrm{B}$ on the expansion from 6 to 10 months, and Panel $\mathrm{C}$ on the expansion from 18 to 36 months. Finally, Table 5 displays alternative estimates for the long-term impact of each reform, by comparing the fraction of women who have returned to the labor market in different months before and after the reform. The raise in leave from 2 to 6 months brought somewhat fewer women back to work. For instance, according to Figure 4, the fraction of women who had not returned to work within 5 years is 1.5 percentage points lower after the reform. The other two expansions, in contrast, had little impact on the share of women who returned to the labor market 3 to 8 years after childbirth. Note that some estimates in Table 5 suggest that these expansions lowered the share. However, Figure 4 reveals that this is due to a downward-sloping aggregate time trend. This illustrates the importance of accounting for 
time trends - in particular, the comparison of women who give birth one year before or after the policy would have given a misleading picture.

The Probability of Working So far, we have ignored the possibility that women may drop out of the labor market after returning, perhaps in order to take care of a second child. Indeed, the transition from home to the labor market seems to be far from permanent. In our sample, the fraction of women who ever returned to the labor market within eight years exceeds the fraction of women who are actually working eight years after childbirth by more than $25 \%$ (69.4\% versus $42.4 \%)$. Next, we report estimates for the impact of maternity leave legislation on the probability of working $t$ months after childbirth (Table 6). The table has the same structure as Table 5. Figure 5 plots the actual as well as predicted fraction of women working $t$ months after childbirth, for women who give birth 6 months before or after the reform. It has the same structure has Figure 4. The table again reveals that the expansions in job-protected leave caused women to delay their return to work (bold columns).

Interestingly, there is little evidence that the expansion in leave from 2 to 6 months lowered the share of women working $t$ months after childbirth - although it lowered the share of women who returned to work within $t$ months after childbirth (see Table 5, Figure 4, Panel A). A possible explanation for this finding is that the women who were discouraged from returning to work because of the expansion in leave coverage would have dropped out of the labor market soon had job-protected leave not been increased. Similarly, the 1992 policy reform that raised job-protected leave from 18 to 36 months appears to have increased the share of women working 36 and 66 months after childbirth by 1 to 2 percentage points - although it had no impact on the share of women who returned to work within 36 or 66 months after childbirth (see Table 5, 
Figure 4, Panel C).

Maternity Benefits or Job Protection? Do mothers delay their return to work because of the extension of job-protected leave or because of the extension of the period during which maternity benefits are paid? The policy reforms in 1979 and 1992 allow us to assess this. The 1979 reform raised job-protected leave from 2 to 6 months. Maternity benefits were paid for a total of 6 months, but at a substantially reduced rate from the 3rd month onwards (one third of women's pre-birth earnings on average). The reform in 1992 increased job-protected leave from 18 to 36 months, but left the period during women are entitled to maternity benefits unchanged at 18 months. Figure 6 plots the fraction of women who return to work $t$ months after childbirth for women who give birth 2 months before or after the policy change ${ }^{15}$. Panel A considers the 1979 reform and Panel B the 1992 reform. After the 1979 reform, about $8 \%$ of mothers return to work around the time when maternity benefits are substantially reduced (i.e. around 2 months after childbirth), while about $35 \%$ of mothers go back to work around the time job-protected leave expires (i.e. in the 5th, 6th or 7 th month after childbirth). After the 1992 reform, about 10\% return to work around the time maternity benefits expire (i.e. around 18 months after childbirth). About the same fraction goes back to work around the time when job-protected leave expires (i.e. around 3 years after childbirth). These findings indicate that women do not only care about maternity benefits, but also about the job guarantee ${ }^{16}$.

\footnotetext{
${ }^{15}$ We did not use women who give birth one month before the change in the law because of measurement error in the month of birth. We also excldue women who give birth in February as they differ from women who give birth in other months - see Section 4.

${ }^{16}$ Burgess et al. (2002) analyze the woman's decision when to return to work after childbirth in the UK, comparing women with and without maternity rights. In line with our results, they find that both job-protected leave and benefits affect the mother's return decision after childbirth.
} 
The Probability of Switching Firms Does an extension in job-protected leave increase the probability that women retain employment with their pre-birth employer? Table 7 estimates the impact of maternity leave legislation on the probability that a woman continues to work for her pre-birth employer $t$ months after childbirth, for women who are working. The table has the same structure as Tables 5 and 6 . A figure similar to Figure 3 and 4 which plots the actual and predicted fractions of women working at their pre-birth employer, for women who give birth 6 months before and after the reform, can be found in Appendix C (Figure C.1). Each reform increased the probability that a woman works for her pre-birth employer shortly after maternity leave expires (i.e. 6, 10, and 36 months after childbirth, respectively; see bold columns). However, for the first and second reform this effect declines fast, suggesting that many women leave their pre-birth employer shortly after returning. We discuss this finding in more detail in Section 6. For the expansion in leave from 18 to 36 months, the effect persists more than 5 years after childbirth.

The next section analyzes the impact of maternity leave legislation on earnings.

\subsection{Maternity Leave and Wages}

There are several channels through which maternity leave may affect wages, and these channels may offset each other. First, if an expansion in maternity leave induces women to postpone their return to work, women will have less time to accumulate labor market skills and existing skills may atrophy while at home. Second, there is some evidence that maternity leave legislation affects women's probability of working for their pre-birth employer (at least initially), thus affecting the probability that women retain valuable firm-specific human capital or productive match capital. This is the main reason put forward in the literature for why maternity leave 
legislation may alleviate adverse effects of career interruptions (e.g. Waldfogel (1998), Klerman and Leibowitz (1997), Hashimoto et al. (2004)). Finally, maternity leave legislation may change the type of women who work, thus affecting earnings through selection. We begin with estimating the impact of maternity leave legislation on earnings. Then, we attempt to shed light on the channels through which maternity leave legislation affects earnings.

Our wage variable is the daily wage, averaged over the days a woman was working for a single employer during the year. Hence, a lower wage may be either due to a lower hourly wage rate, or due to fewer hours worked per day.

Main Effect Table 9 displays alternative estimates for the impact of the three main policy reforms on the daily wage of women working $t$ months after childbirth. Each row lists the birth month we use to estimate this impact. Figure 7 plots the actual and predicted average wage against the month of birth. We only use 12 birth months (as opposed to 24 in Figure 4 and 5) in order to make sure that all wage observations refer to the same calendar year (see Appendix A.1 for more details). A 'placebo' figure that plots actual and predicted average wages in the same birth months, but in a year in which there was no change in maternity leave legislation, can be found in Appendix C (Figure C.2).

The results vary by policy reform. Both Table 9 and Figure 7 show that the 1979 expansion in job-protected leave from 2 to 6 months significantly lowered wages for working women, even 8 years after childbirth (Panel A). The 1986 expansion from 6 to 10 months, in contrast, had no significant impact on daily wages. Finally, there is some tentative evidence that the 1992 expansion from 18 to 36 months increased daily wages for working women up until 66 years after childbirth. While the point estimate is robust across alternative specifications and estimation 
methods, it is not always statistically significant. Also notice that this reform raised wages of women working 30 months after childbirth. A natural explanation for this finding is that women who are working 30 months after childbirth although they are eligible for 36 months of job-protected leave are positively selected in terms of their productivity.

Channels How does maternity leave legislation affect wages? Why does the increase in jobprotected leave from 2 to 6 months lower wages, and why does the increase in job-protected leave from 18 to 36 months (possibly) increase wages? We employ an Oaxaca-Blinder decomposition in order to investigate the extent to which differences in the number of months worked after childbirth, in the probability of working for the pre-birth employer and in the probability of working full-time can account for the difference in wages before and after the policy reform. We estimate the following log-wage regression for employed women, separately for women who give birth shortly before or shortly after a change in maternity leave legislation, and separately for different points of time after childbirth:

$$
\ln w_{i j t}=\beta_{0 t}^{j}+\beta_{1 t}^{j} \operatorname{Exp}_{i t}+\beta_{2 t}^{j} S E_{i t}+\beta_{3 t}^{j} F T_{i t}+u_{i t}^{j}, \quad j=\text { before } / \text { after. }
$$

Here, $i$ denotes individuals, $t$ denotes the time since childbirth, and $j$ denotes whether the woman gives birth before or after the policy reform; Expijt is the accumulated number of months worked by month $t$ after childbirth, $S E_{i j t}$ is a dummy variable equal to 1 if the woman works at her pre-birth employer, and $F T_{i j t}$ is a dummy variable equal to 1 if the woman is working full-time. Using these estimates (which we denote by a hat), we decompose the total difference in log-wages before and after the policy change into an explained and unexplained 
part:

$$
\begin{aligned}
& \underbrace{\left(\overline{\operatorname{Exp}}_{t}^{\text {after }}-\overline{\operatorname{Exp}}_{t}^{\text {before }}\right) \widehat{\beta}_{1 t}^{\text {after }}+\left(\overline{S E}_{t}^{\text {after }}-\overline{S E}_{t}^{\text {before }}\right) \widehat{\beta}_{2 t}^{\text {after }}+\left(\overline{F T}_{t}^{\text {after }}-\overline{F T}_{t}^{\text {before }}\right) \widehat{\beta}_{3 t}^{\text {after }}} \\
& \text { exp lained } \\
& \Delta \overline{\ln }_{t}= \\
& \left(\widehat{\beta}_{0 t}^{\text {after }}-\widehat{\beta}_{0 t}^{\text {before }}\right)+\left(\widehat{\beta}_{1 t}^{\text {after }}-\widehat{\beta}_{1 t}^{\text {before }}\right) \overline{\operatorname{Exp}}_{t}^{\text {before }} \\
& +\left(\widehat{\beta}_{2 t}^{\text {after }}-\widehat{\beta}_{2 t}^{\text {before }}\right) \overline{S E}_{t}^{\text {before }}+\left(\widehat{\beta}_{3 t}^{\text {after }}-\widehat{\beta}_{3 t}^{\text {before }}\right) \overline{F T}_{t}^{\text {before }} \\
& \text { un exp lained (selection) }
\end{aligned}
$$

We refer to the unexplained component as 'selection', reflecting that maternity leave legislation may change the type of women who work.

Row (1) in Table 8 reports results. Row (2) reverses the order of the decomposition, and evaluates the explained component using the coefficients from the before regression. The table also reports the mean difference in characteristics before and after the policy reform. Results are based on women who give birth 3 months before or after the reform, and exclude February births; results are similar when a different sample is used.

The delay in the return to work - i.e. the lower number of months worked since childbirth - predicts a lower wage after each policy reform. This effect is rather large, usually between 1 and 2 percentage points; we discuss the magnitude of our estimates in more detail in Section 6. Note that it captures two effects: First, one more month away from work results in more human capital depreciation; second, it results in less human capital accumulation. This suggests that career interruptions due to childbirth are an important determinant of the family gap. Differences in the probability of working at the pre-birth employer as well as in full-time work, in contrast, hardly contribute to the difference in wages before and after a policy reform. 
Although the 1992 policy reform significantly raised the probability that a woman is employed at her pre-birth employer 3 or 5 years after childbirth, its impact on wages is too small to be quantitatively important.

The lower work experience can almost entirely account for the lower wage 3 years after childbirth after the 1979 policy reform; here, the unexplained - i.e. the selection - component is small and not statistically different from zero. Five years after childbirth, the selection component becomes negative and marginally significant. In contrast, the selection component is substantial and positive for the two later reforms. For the 1986 reform, the selection effect almost exactly offsets the negative effect from delaying the return to work. For the 1992 reform, the selection effect even exceeds the negative effect from the lower work experience, resulting in a higher wage after the reform. In both cases, the selection effect declines with time since childbirth; 90 months after childbirth, it becomes small and statistically indistinguishable from zero (not reported).

What explains this large selection effect? It must be driven by the women who make full use of the maternity leave legislation and return to work exactly when job-protected leave expires i.e. by those women whose return decision is affected by the maternity leave legislation. How do mothers who are affected by the maternity leave legislation differ from those who are not? When the leave period is 2 months, women who return to work after 2 months earn a higher wage than women who return at other times, both before and after childbirth. Hence, these mothers are positively selected. In contrast, when the leave period is longer than 2 months, mothers who return to work exactly when job-protected leave expires become negatively selected, and the more so the longer the leave period. This is what we would expect if the more productive women return to work earlier after childbirth. Moreover, with time after childbirth, the share 
of women who return to work after the expiration of the leave period increases. This reinforces the difference in post-birth wages of women affected and not affected by the legislation when the leave period is 2 months, but reduces it for longer leave periods.

To better see how this is related to the selection effect in (1), write the average difference in the post-birth wage of mothers who give birth before and after the reform as

$$
\begin{aligned}
& \Delta \overline{\ln }_{t}=\left\{P_{A t}^{\text {after }} w_{A t}^{\text {after }}+\left(1-P_{A t}^{\text {after }}\right) w_{\overline{A t}}^{\text {after }}\right\}-\left\{P_{A t}^{\text {before }} w_{A t}^{\text {before }}+\left(1-P_{A t}^{\text {before }}\right) w_{\overline{A t}}^{\text {before }}\right\} \\
& =\quad\left[P_{A t}^{\text {after }}\left(w_{A t}^{\text {after }}-w_{A t}^{\text {before }}\right)+\left(1-P_{A t}^{\text {after }}\right)\left(w_{\bar{A} t}^{\text {after }}-w \frac{\text { before }}{A t}\right)\right]+ \\
& \left\{P_{A t}^{\text {after }}-P_{A t}^{\text {before }}\right\}\left\{w_{A t}^{\text {before }}-w_{\overline{A t}}^{\text {before }}\right\} .
\end{aligned}
$$

Here, $P_{A t}^{j}(j=$ before, after $)$ denotes the share of women affected by the reform, while $w_{A t}^{j}$ and $w_{\bar{A} t}^{j}$ denote the average wage earned by women who are and are not affected by the reform. The last term in curly brackets - i.e. the difference in the share of women who go back to work exactly when leave expires after and before the reform multiplied by the difference in the wage of women who are and are not affected by the reform - is related to the selection effect. Recall from Figure 2 that the longer the job-protection period, the lower the share of women affected by maternity leave legislation. Hence, $P_{A t}^{\text {after }}-P_{A t}^{\text {before }}$ is negative for all three reforms, but more so for the two later expansions. Moreover, $w_{A t}^{\text {before }}-w_{\overline{A t}}^{\text {before }}$ is positive for the expansion in leave from 2 to 6 months, accounting for the negative selection effect; but negative for the expansions in leave from 6 to 10 and 18 to 36 months, accounting for the positive selection effect. Moreover, $w_{A t}^{\text {before }}-w_{\bar{A} t}^{\text {before }}$ declines with time since childbirth for both the 1986 and 1992 reform, thus accounting for the decline in the selection effect over time. In contrast, $w_{A t}^{\text {before }}-w \frac{\text { before }}{A t}$ increases with time since childbirth for the 1979 reform, thus accounting for why the selection 
effect becomes more negative over time.

\section{Discussion and Conclusion}

We find strong evidence that each expansion in leave coverage induced women to delay their return to work. The delay is strongest for the increase in job-protected leave from 2 to 6 months in 1979, and weakest for the increase from 18 to 36 months in 1992. Hence, each expansion succeeded in increasing the time women spend with their children after childbirth. However, whether this leaves children better off - which was the main motivation behind the 1986 and 1992 reform - remains an open question ${ }^{17}$.

Despite this strong short-term effect, there is little evidence that the expansions had any long-term impact on mothers' labor force participation rates. For instance, according to Figure 4, Panel A and B, the point estimate of the impact of the raise in job-protected leave from 2 to 6 months in 1979 (6 to 10 months in 1986) on the probability of working 5 years after childbirth is $-0.003(0.004)$, with a standard error of $0.006(0.004)$. Given the precision of these estimates, we are able to rule out the hypothesis that the 1979 (1986) expansion raised labor force participation by more than 0.7 (1) percentage points at a 5 percent level. Hence, these expansions failed to increase employment continuity of mothers after childbirth. This, however, was an important motivation behind similar reforms recently implemented in other countries. However, there is some evidence that the effect of leave coverage on labor force participation is non-linear, as the expansion from 18 to 36 months increased the share of women who are working 66 months after childbirth by about 1.5 percentage points.

\footnotetext{
${ }^{17}$ Ruhm (2000) and Tanaka (2005) provide some evidence that expansions in leave coverage reduces child mortality. For a recent paper on the impact of maternity leave legislation on child development, see Baker and Milligan (2006).
} 
Our estimates also imply that the expansions in leave coverage did not lower mothers' longrun labor force participation rates. We are able to rule out the hypothesis that the expansion in leave from 2 to 6 months in 1979 (6 to 10 months in 1986) decreased the share of women working 5 years after childbirth by more than $1.28(0.3)$ percentage points at a 5 percent level. This suggests that time away from work has only a small causal impact on future labor market attachment. Such a causal impact could arise because of human capital depreciation: If women's employment opportunities decline with the time away from work, women may become less and less likely to return to work the more time they spend away from work. Alternatively, more time spent with children may cause mothers to want to spend even more time with their children. The detrimental effect that time away form work may have on future labor market attachment is at the heart of the current debate on the design of social assistance and welfare programs. In particular, the changes in US welfare and tax policy between 1984 and 1996 were designed to encourage work by single mothers, and an important motivation behind the changes was that time away from work may lower women's future labor market attachment (e.g. Meyer and Rosenbaum (2001), Blank (2002)).

Our results on the long-run effect of expansions in leave coverage on a mother's labor supply further suggest that the expansions had little effect on the spacing of subsequent births ${ }^{18}$.

How did the expansions in leave coverage affect wages? Did the delay in the return to work caused by the expansions in leave coverage lead to lower wages because mothers lost more and accumulated less human capital after childbirth? We find this to be the case for the expansion

\footnotetext{
${ }^{18}$ This is different from Lalive and Zweimüller $(2005,2006)$ who find that an increase in leave coverage from 1 to 2 years in Austria lowered the share of women who returned to work within 3 and 8 years of childbirth by 12 and 8 percentage points, respectively. The policy also increased the probability of having a second child within 3 years by 4.9 percentage points. The Austrian reform provided a strong financial incentive for women to become pregnant with a second child within two years, prior to the expiration of the leave period. Since in Germany women are entitled to maternity benefits even if they were not employed, this incentive is weaker in Germany.
} 
in leave coverage from 2 to 6 months. For the expansion in leave from 6 to 10 months and 18 to 36 months, the delay in the return to work alone also reduced wages. However, for these expansions the negative human capital effect is offset by a positive selection effect, resulting in a zero or even positive overall wage effect. How important is the wage loss due to more time away from work quantitatively? The delay in the return to work typically predicts a 1.4 percentage point lower post-reform wage, with estimates ranging from -2.5 percentage points for the 1992 reform, and -0.9 percentage points for the 1986 reform (Table 8). If we divide these estimates by the difference in the months worked before and after the reform, we get numbers ranging from $0.8 \%$ (e.g. 1986 policy reform, 66 months after childbirth) to $1.3 \%$ (e.g. 1979 reform, 3 years after childbirth) per month - implying that one months more away from work lowers wages by about $1 \%$. This is a large effect. It is, however, somewhat smaller than the corresponding OLS or first-difference estimate. When we regress wages three years after childbirth on the number of months worked since childbirth, indicator variables for whether the woman is working full-time or for her pre-birth employer, as well as on birth year and birth month dummies, our estimate for one additional month of post-birth work experience is $1.45 \%$. If instead we regress the change in the wage three years after childbirth and the pre-birth wage on the above variables, our estimate reduces slightly to $1.33 \%$. Several studies for Germany report estimates of similar magnitude. For instance, Kunze and Ejrnaes (2004) report that for the medium-skilled, one year out of work after child birth is associated with a wage loss of 12\%; see also Kunze (2002) and Beblo and Wolf (2002). Compared to other countries, these estimates are large ${ }^{19}$. A possible explanation for this is that German firms find it increasingly costly to keep the same job available the longer a woman stays away from work, and assign her

\footnotetext{
${ }^{19}$ See e.g. Albrecht et al. (1999) for Sweden, Datta Gupta and Smith (2002) for Denmark, and Light and Ureta (1995) and Spivey (2005) for the US.
} 
to a job that is comparable to the one she held prior to childbirth once she returns to work resulting in a lower match quality.

Proponents of maternity leave policies have argued that leave policies may raise mothers' wages through the retention of firm-specific human or match capital (see e.g. Waldfogel (1998), Hashimoto et al. (2004) for a discussion). We find little support for this claim. While there is some evidence that the expansion in leave coverage initially increased the mother's employment with her pre-birth employer, its impact on wages is very small; the negative impact of an expansion in leave coverage on wages caused by the delay in the return to work is by far more important. These results indicate that, as first argued by Mincer and Polacheck (1974), career interruptions due to childbirth are an important determinant of the family and gender wage gap. Our results are also supportive of the hypothesis that the main driving forces behind the relative improvement of women's wages in the US during the 1980s and 1990s is the increase in the labor market attachment of women (Blau and Kahn (2000)). Our findings further cast some doubt on whether expansions in leave coverage are successful at promoting gender equality.

Our final comment relates to firms' possibilities of avoiding the maternity leave legislation. Our results on the impact of the expansions in leave coverage on the probability to work for the pre-birth employer suggest that many women leave their pre-birth employer soon after they returned to work (Table 7, Figure C.1). Recall that we imposed the restriction that women have to return to work for at least two consecutive months; if we drop this restriction, this effect becomes even more pronounced. For instance, about $7 \%$ of women who are eligible for 2 or 6 months of leave return to work exactly when leave expires, but leave their employer 1 or 2 months later. This share is somewhat lower for the longer leaves, but still substantial (between 2 and $4 \%$ ). The majority of these women claim unemployment benefits afterwards and do not 
return to work for many years. What explains this finding? Once mothers return to work, the regular employment protection rules apply and it becomes possible for firms to lay off women ${ }^{20}$. A possible interpretation of this finding therefore is that some firms avoid the law by laying off mothers soon after they return to work. There is, however, an alternative interpretation: Mothers play the system and return to work only in order to qualify for unemployment benefits.

To conclude, the primary effect of the expansions in leave coverage is the delay in the return to work. This may increase overall welfare if more time at home after childbirth improves the mother's health or the child's cognitive and emotional development. However, the delay in the return to work comes at a cost. Our estimates suggests that one months away from work lowers wages by about $1 \%$. Our results also cast some doubt on whether expansions in leave coverage are successful at promoting employment continuity or gender equality.

\footnotetext{
${ }^{20}$ See Bauer, Bender, and Bonin (2004) for more details on dismissal protection in Germany. According to the Protection Against Dismissal Act (Kuendigungsschutzgesetz), firing is only allowed for cause such as health, bad conduct, or redundancy. For most of the period considered, the advance notice period was 6 weeks for white-collar (Angestellte) and 2 weeks for blue-collar workers (Arbeiter). Importantly, small firms -where a substantial fraction of the German workforce is employed- are excempt from these laws.
} 


\section{References}

[1] Anderson, D., Binder, M., and K. Krause (2002): "The Motherhood Wage Penalty: Which Mothers Pay it and Why?", American Economic Review, 2, 354-358.

[2] Baker, M. and K. Milligan (2005): "How Does Job-Protected Maternity Leave Affect Mothers' Employment and Infant Health?", NBER Working Paper No. 11135.

[3] Baker, M. and K. Milligan (2006): "The Early Development and Health Benefits of Maternity Leave Mandates", unpublished Working Paper, University of British Columbia.

[4] Bauer, T.K., S. Bender, and H. Bonin (2004): "Dismissal Protection and Worker Flows in Small Establishments", IZA Discussion Paper No. 1105.

[5] Baum, C. L. (2003a): "The Effects of Maternity Leave Legislation on Mothers' Labor Supply after Childbirth", Southern Economic Journal, 69, 772-99.

[6] Baum, C. L. (2003b): "The Effect of State Maternity Leave Legislation and the 1993 Family and Medical Leave Act on Employment and Wages", Labour Economics, 10, $573-96$.

[7] Beblo, M. and E. Wolf (2002): "Wage Penalties for Career Interruptions: An Empirical Analysis for West Germany", ZEW Discussion Paper No. 02-45.

[8] Berger, L. M. and J. Waldfogel (2004): "Maternity Leave and the Employment of New Mothers in the United States", Journal of Population Economics, 17, 331-49.

[9] Blank, R. (2002): "Evaluating Welfare Reforms in the United States", Journal of Economic Literature, XL, 1105-1166.

[10] Blau. F.D. and L. Kahn (2000): "Gender Differences in Pay", Journal of Economic Perspectives, 14, 75-99.

[11] Bundesministerium für Familie, Senioren, Frauen und Jugend (2000): "Bundesstatistik Erziehungsgeld 2000".

[12] Burgess, S., Gregg, P., Propper, C., E. Washbrook, and the ALSPAC Study Team (2002): "Maternity Rights and Mothers' Return to Work", CMPO Discussion Paper No. $02 / 055$.

[13] Datta Gupta, N. and N. Smith (2002): "Children and Career Interruptions: The Family Gap in Denmark", 69, 609-629.

[14] Dickert-Conlin, S. and A. Chandra (1999): "Taxes and the Timing of Births", Journal of Political Economy, 107, 161-177.

[15] Ekberg, J., R. Eriksson, and G. Friebel (2005): "Parental Leave: A Policy Evaluation of the Swedish 'Daddy-Month' Reform", IZA Discussion Paper 1617. 
[16] Engstler, H. and S. Menning (2003): "Die Familie im Spiegel der amtlichen Statistik", Bundesministerium für Familie, Senioren, Frauen und Jugend.

[17] Hanratty, M. and Trzcinski, E. (2005): "Impact of Family Leave in Canada and the United States on Post-Birth Employment Dynamics of Women", unpublished Working Paper, Humphrey Institute of Public Affairs, University of Minnesota.

[18] Harkness, S. and J. Waldfogel (2003): "The Family Gap in Pay: Evidence from Seven Industrialized Countries", Research in Labor Economics, 17, 331-349.

[19] Hashimoto, M., Percy, R., Schoellner, T., and B. A. Weinberg (2004): "The Long and Short of It: Maternity Leave Coverage and Women's Labor Market Outcomes", IZA Discussion Paper No. 1207.

[20] Joshi, H. (1991): "Sex and Motherhood as Handicaps in the Labor Market", in: Groves, D. and Maclean, M. (eds), Women's Issue in Social Policy, London.

[21] Klerman, J. A. and A. Leibowitz (1997): Labor Supply Effects of State Maternity Leave Legislation", in: Blau, F. D. and R. G. Ehrenberg (eds.), Gender and Family Issues in the Workplace. New York: Russell Sage Foundation, pp. 65-85.e?", Cambridge Journal of Economics, 23, 543-564.

[22] Kunze, A. (2002): "The Timing of Careers and Human Capital Depreciation", IZA Discussion Paper No. 509.

[23] Kunze, A. and M. Ejrnaes (2004): "Wage Dips and Drops around First Birth", IZA Discussion Paper No. 1011.

[24] Lalive, R. and J. Zweimüller (2005): "Does Parental Leave Affect Fertility and Returnto-Work? Evidence from a 'True Natural Experiment'", IZA Discussion Paper No. 1613.

[25] Lalive, R. and J. Zweimüller (2006): "Estimating the Effect of Maximum Parental Leave Duration on Mothers' Subsequent Labor Market Careers", University of Zürich, mimeo.

[26] Light, A. and M. Ureta (1995): "Early Career Work Experience and Gender Wage Differentials", Journal of Labor Economics, 13, 121-154.

[27] Meyer, B.D. and D.T. Rosenbaum (2001): "Welfare, The Earned Income Tax Credit, and the Labor Supply of Single Mothers", Quarterly Journal of Economics, 116, 1063-1114.

[28] Mincer, J. and S.W. Polachek (1974): "Family Investment in Human Capital: Earnings of Women", Journal of Political Economy (March 1974 Supplement), S76-S108.

[29] Ondrich, J., C. K. Spiess, Q. Yang and G. G. Wagner (2003a): "The Liberalisation of Maternity Leave Policy and the Return to the Work of Childbirth in Germany", Review of Economics of the Household, 1, 77-110. 
[30] Ondrich, J., Spiess, C. K. and Q. Yang (2003b): "Changes in Women's Wages after Parental Leave", Schmollers Jahrbuch: Zeitschrift fur Wirtschafts- und Sozialwissenschaften/Journal of Applied Social Science Studies, 123, 125-37.

[31] Phipps, S. Burton, P., and L. Lethbridge (2002): "In and Out of the Labor Market: Longterm consequences of Child-Related Interruptions to Women's Paid Work", Canadian Journal of Labor Economics, 34, 411-429.

[32] Rosenschon, A. (2001): "Familienförderung in Deutschland - eine Bestandsaufnahme", Kieler Arbeitspapier Nr. 1071.

[33] Ruhm, C.J. (1998): "The Economic Consequences of Parental Leave Mandates: Lessons from Europe", Quarterly Journal of Economics, 113, 285-317.

[34] Ruhm, C. J., Teague, J. (1997): "Parental Leave Policies in Europe and North America", in: Blau, F. D. and R. G. Ehrenberg (ed.), Gender and Family Issues in the Workplace, New York: Russell Sage Foundation, pp. 133-156.

[35] Ruhm, C. (2000): "Parental Leave and Child Health", Journal of Health Economics, 19, 931-960.

[36] Spivey, C. (2005): "Time Off at What Price? The Effects of Career Interruptions on Earnings", Industrial and Labor Relations Review, 59, 119-140.

[37] Tanaka, S. (2005): "Parental Leave and Child Health across OECD Countries", Economic Journal (Features), 115, F7-F28.

[38] Waldfogel, J. (1997): "Working Mothers Then and Now: A Cross-Cohort Analysis of the Effects of Maternity Leave on Women's Pay", in: Blau, F. D. and R. G. Ehrenberg (ed.), Gender and Family Issues in the Workplace, New York: Russell Sage Foundation, pp. 92-127.

[39] Waldfogel, J. (1998a): "The Family Gap for Young Women in the United States and Great Britain: Can Maternity Leave Make a Difference?" Journal of Labor Economics, 16, $505-45$.

[40] Waldfogel, J. (1998b): "Understanding the 'Family Gap' in Pay for Women with Children", Journal of Economic Perspectives, 12, 137-152.

[41] Waldfogel, J. (1999): "The Impact of the Family and Medical Leave Act", Journal of Policy Analysis and Management, 18, 281-301.

[42] Waldfogel, J., Y. Higuchi, and M. Abe (1999): "Family Leave Policies and Women's Retention after Childbirth: Evidence from the United States, Britain, and Japan", Journal of Popluation Economics, 12, 523-545. 


\section{Appendix}

\section{Appendix A: Data Description and Sample Selection}

\section{A.1: Main Data (BLH)}

Our main data comes from Social Security Records (the so-called Beschäftigten - Leistungsempfänger - Historik, BLH). The data is available from 1975 to 2001. It allows us to construct the complete work history - including time spent in unemployment and on leave of absence for every woman covered by the social security system. In particular, we know the exact day a woman started and stopped working, switched employers, became unemployed, or went on leave. For each employed woman, we observe at least one wage per year. If the woman switched employers during the year, we observe more than one wage. As with many administrative data sets, wages are top coded at the highest level of earnings subject to social security contributions. This is not a serious problem in our data, since less than $1 \%$ of pre- and post-birth wages are right-censored.

Sample Selection We drop all dual employment relationships and all working spells with reported wages lower than the censoring limit for which social security contributions have to be paid. Marginal jobs, i.e. jobs with less than 15 hours per week, are likewise excluded.

From this data base, we select all spells of all women between 16 and 45 years of age with at least one leave spell between January 1978 and December 1993. We drop all women whose first spell classifies them as a foreigner or as from East Germany. We then impose the following restrictions on leave spells:

- the leave spell must not start on the first of a month;

- the leave spell must last at least 2 months;

- the leave spell must not be preceded by a spell in apprenticeship training;

- the leave spell must not be preceded by a spell in unemployment.

Why do we focus on labor market outcomes 18, 30, 42, .. months after childbirth for the reforms in 1986 and 1992? In our data, firms have to report the exact date the employment relationship started or ended. Hence, we know whether a woman has returned to work or is working at any point in time after childbirth (either at her pre-birth employer or at another firm). This is not true for wages. Table A.1 illustrates how wages are measured in our data.

Consider a woman who gives birth in December 1985 and is entitled to 6 months of jobprotected leave. Suppose she returns to work at the end of the leave period in July 1986. 
Further suppose that for the next 3 years she keeps working for a pre-birth employer (woman 1 in Table A.1). For this woman, we observe the average daily wage between July and December 1986, i.e. the average daily wage between the 7 th and 12 th month after childbirth. The next wage observation refers to January to December 1987, i.e. to the 13th to 24th months after childbirth, and so on. Next, consider a woman who also gives birth in December 1985, returns to work in July 1986, but switches firms in April 1987 (woman 2 in Table A.1). For this woman, the first three wage spells refer to the 7 th to 12 th month, 13th to 16th month, and 17th to 24th month after childbirth. Contrast this with a woman who gives birth in January 1986, is eligible to 10 months of job-protected leave, returns to work in November 1986 and keeps working for the same employer for the next three years (woman 3 in Table A.1). For this woman, we observe the average daily wage between November and December 1986, i.e. between the 10th and 11th month after childbirth. The second wage observation refers to the 12th to 23rd month after childbirth. For woman 1, the spell 12 months after childbirth refers to the 7th to 12th month and calendar year 1985. For woman 2, in contrast, it refers to the 12th to 23rd month after childbirth and calendar year 1986. These two spells may not be comparable. As the spell 18 months after childbirth refers to 1986 for both women, we prefer to look at labor market outcomes 18, 30, 42 etc. months after childbirth, rather than at 12, 24, 36 etc. months.

In principle, we could have defined the spell one year after childbirth to be the second observed wage spell for woman 1. In fact, this spell is the same as the spell referring to 18 months after childbirth - unless the woman switches firms during that year. While this leads to similar results, we prefer to use the spell 18 months after childbirth as an unusual number of women switch firms at the first of January each calendar year.

Notice that when looking at the spell 18 months after childbirth, women who give birth in December have one additional month of post-birth work experience than women who give birth in January. This is even more of a problem when comparing women who give birth in October or November with women who give birth in February or March. To see how this affects our results, we compare women who give birth in the same months in a year in which there was no change in maternity leave legislation.

As the first policy reform happened in May 1979, the wage spell referring to the first, second, third etc. year after childbirth, for women who give birth shortly before and after the reform, refer to the same calendar year. Hence, for this reform, we focus on labor market outcomes 1, 2,3 etc. years after childbirth.

\section{Variable definition}

- education Women with less than 3/10 of spells as university graduates and at least 3/10 of spells as apprentices are classified as apprentices or medium-skilled. Women with at least 3/10 of spells as university graduates are classified as high-skilled. All other women are classified as low-skilled. 
- return to work: We require women to return to work for at least two consecutive months. We impose this restriction because up to $5 \%$ of women return to work for less than two months, typically right when job-protected leave expires - see also Section 6. Many of these women take up permanent employment only many years later. Results are similar if a more stringent definition, such as working for at least six consecutive months, is used.

- working $t$ months after childbirth: A woman is considered to be working $t$ months after childbirth if at $t-1, t$, or $t+1$, if she is paying social security contributions and has returned to work. We find it convenient to define the variable in this way because in about $30 \%$ of the cases, we over- or underestimate the child's birth month by one month.

- wages $t$ months after childbirth (working women only): The wage variable is the daily wage, averaged over the length of the employment spell. If we observe two wage spells that refer to $t$ months after childbirth (this happens if a woman switches employers exactly $t$ months after childbirth), we use the first wage spell. If a woman is not employed $t$ months after childbirth, but is employed $t-1$ or $t+1$ months after childbirth (and is thus considered as working), we use the wage referring to the $t-1$ or $t+1$ spell.

- working full-time $t$ months after childbirth (working women only): Full-time work refers to work between 20 and 30 hours per week. As with wages, we use the first spell if we observe two spells that refer to $t$ months after childbirth. If a woman is not employed $t$ months after childbirth, but is so $t-1$ or $t+1$ months after childbirth, we use the full-time status referring to the $t-1$ or $t+1$ spell.

- working at pre-birth employer $t$ months after childbirth: The employer identification number refers to establishments.

- Pre-birth characteristics (age, wage, working full-time, occupation): Pre-birth characteristics are measured 9 months before childbirth. In the rare event that a woman is not working 9 months before childbirth, pre-birth characteristics are measured at the last valid employment and wage spell prior to childbirth.

\section{A.2: Auxiliary Data: The German Pension Register}

The Pension Register is a 1\% random sample drawn from the data base described above. This data has the exact same structure as our main data, except that it additionally includes the birth year and birth month of each child. In principle, it is available from 1975 to 1995. However, reliable data on the fertility history exists only from 1986 onwards. We construct three samples.

- Sample 1: Our first sample consists of all women with at least one leave spell $(2 \leq$ btyp $\leq .6)$ between January 1986 and December 1992. We drop leave spells that are shorter 
than 2 months, leave spells where the woman was younger than 16 or older than 45 , leave spells that were preceded by a spell in registered unemployment, and leave spells during apprenticeship training. We use this data to analyze how many leave spells are due to childbirth (see Table 2).

- Sample 2: Our second sample includes all women who give birth between January 1986 and December 1992 and go on maternity leave. We drop leave spells that are shorter than 2 months, leave spells where the woman was younger than 16 or older than 45, leave spells that were preceded by a spell in registered unemployment, and leave spells during apprenticeship training. We use this sample to analyze the relationship between the month a woman goes on maternity leave and the month she gives birth (see Table 3).

- Sample 3: For the third sample, we select all women who have given birth between January 1986 and December 1992. We use this sample to analyze the number of women who give birth take maternity leave (see Table 4).

We define variables as follows.

- maternity leave: A woman takes maternity leave if in the period 6 months before and 3 months after the child's birthday, the btyp variable takes a value between 2 and 6 at least once. We have experimented with more and less flexible definitions (e.g. up to 9 months or only 3 months before the child's birthday). This has little effect on our results.

- childbirth: The pension register records the year and birth month of all children born after December 1985. There is an additional variable in the data set that indicates whether a woman is eligible for a pension because of childbirth (ZU_VDR). In some rare cases, a woman has given birth according to this variable, but there is no recorded birth. In Table 2 , a leave spell is considered to be a true maternity leave spell if a birth (including births based on the ZU_VDR variable) is recorded 3 months before or 6 months after the start of the leave spell. Alternative definitions have little effect on our results.

\section{Appendix B: Identification strategy, robustness checks}

Figure B.1 plots the fraction of mothers who take maternity leave by birth month. The (blue) dots refer to the average fraction of women who give birth in a certain month and take maternity leave; the (red) solid line are predicted averages fitting a quadratic time trend. The red vertical lines indicate an extension in job-protected leave. While the fraction of mothers on leave varies substantially by birth months, there is little evidence for a discontinuous jump when maternity leave was extended, except possibly for the increase in job-protected leave from 15 to 18 months. However, this jump is not statistically significant, and disappears if we allow for polynomial time trends of higher order. 
Table B.1 reports results from linear probability models that control for a time trend in various ways. Each regression allows for a separate discontinuous jump whenever maternity leave was extended. The results indicate that there is no significant change in the incidence in leave taking following an extension in job-protected leave. However, due to the small sample size, standard errors are rather large. 
Figure 1: Maternity Leave Legislation in Germany (Selected Reforms)

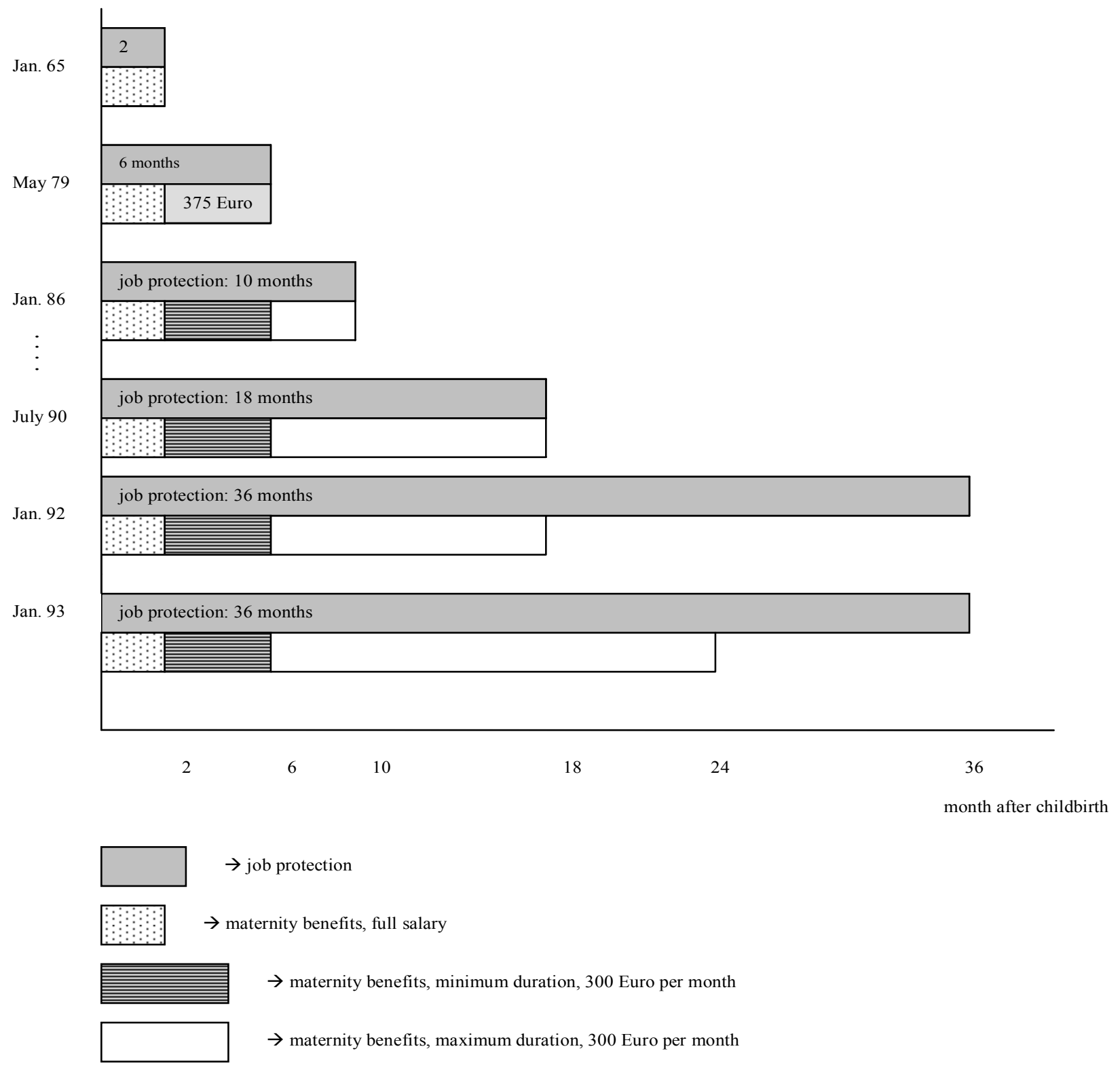

Note: Since 1986, all women -employed before childbirth or not- are entitled to a maternity benefit of 300 Euro per month for a minimum of 6 months. From the 7th month onwards, maternity benefits are means-tested, and depend on the annual net family income two years before childbirth. The majority of women receive benefits longer than 6 months.

In January 1988, maternity leave was extended from 10 to 12 months. Two further changes occurred in July 1989 and July 1990 when maternity leave was increased to 15 and 18 months, respectively. 
Table 1: Differences in Pre-Birth Characteristics of Women Who Give Birth Shortly Before and Shortly After a Change in Legislation

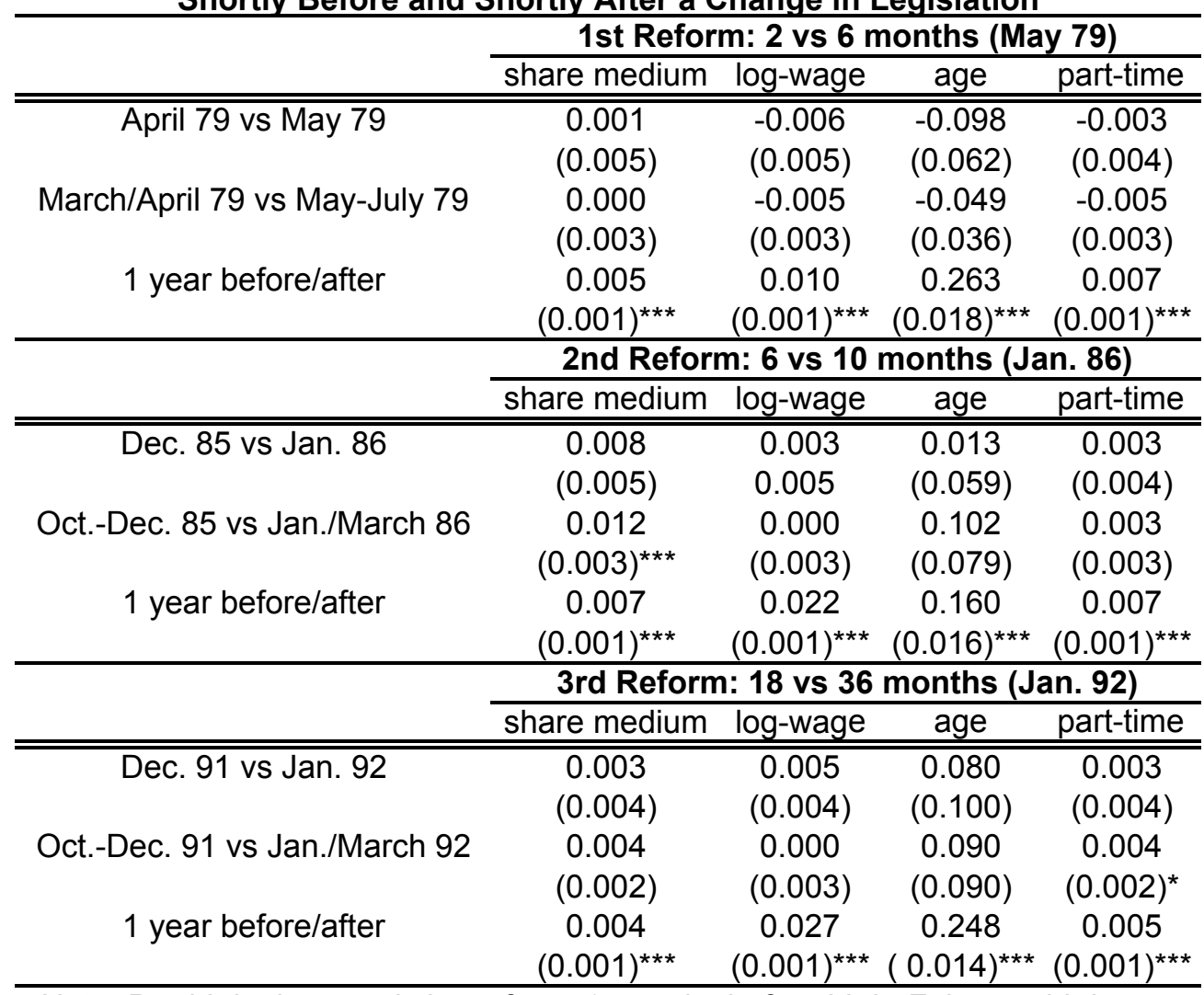

Note: Pre-birth characteristics refer to 9 months before birth. February births are excluded. *Statistically significant at 0.10 level, ${ }^{* *}$ at 0.05 level, ${ }^{* *}$ at 0.01 level. 
Table 2: How Many Leave Spells are due to Childbirth?

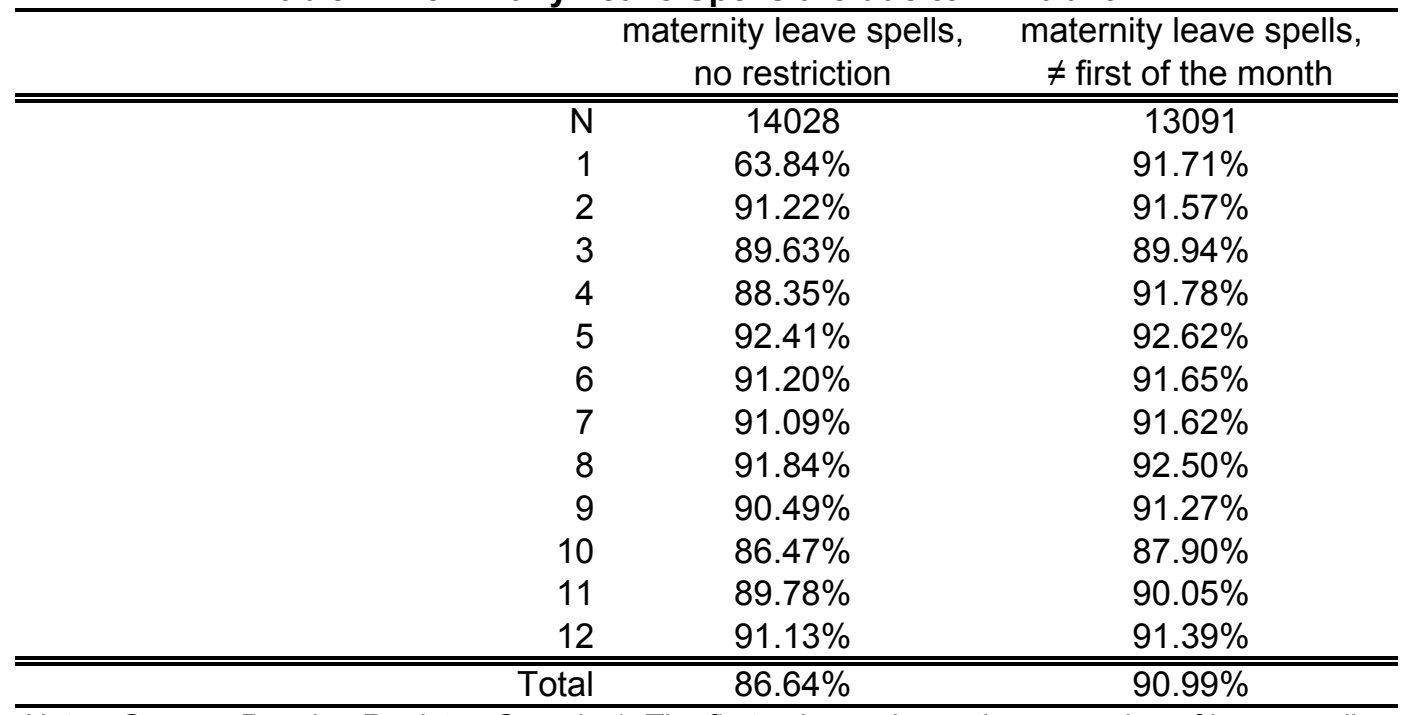

Note: German Pension Register, Sample 1. The first column shows the proportion of leave spells that are due to child birth in the raw data. The second column shows the proportion of leave spells that are due to child birth after dropping leave spells that start at the first of a month have been dropped.

Table 3: True Birth Month and Imputed Birth Month

\begin{tabular}{cc|ll}
\hline \hline birth occured ... & & & \\
more than one month before ... & $0.64 \%$ & birth occured ... & $13.09 \%$ \\
one month before .... & $12.50 \%$ & before .... & $69.80 \%$ \\
in the same month as ... & $69.80 \%$ & in the same month as ... & $17.11 \%$ \\
one month after ... & $11.88 \%$ & after ... & the imputed birth \\
more than one month after ... & $5.23 \%$ & & \\
the imputed birth & & & \\
\hline \hline
\end{tabular}

Note: German Pension Register, Sample 2. N=11198. 
Table 4: Data Overview

\begin{tabular}{|c|c|c|c|c|c|c|c|}
\hline \multicolumn{8}{|c|}{ 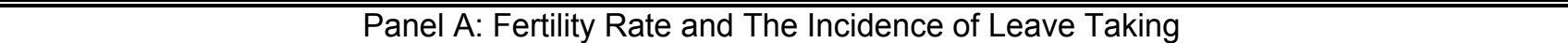 } \\
\hline 1 & 2 & 3 & 4 & 5 & 6 & 7 & 8 \\
\hline year & $M L$ & fertility rate & \# births & $\mathrm{N}$ (\# data) & ML: N / \# births & ML: all (PR) & ML: employed (PR) \\
\hline 1977 & 2 & 1.385 & 504,073 & 158,985 & $31.54 \%$ & & \\
\hline 1978 & 2 & 1.378 & 501,073 & 167,896 & $33.51 \%$ & & \\
\hline 1979 & 216 & 1.377 & 506,242 & 185,980 & $36.74 \%$ & & \\
\hline 1980 & 6 & 1.443 & 539,962 & 217,026 & $40.19 \%$ & & \\
\hline 1981 & 6 & 1.433 & 544,548 & 225,955 & $41.49 \%$ & & \\
\hline 1982 & 6 & 1.405 & 548,192 & 227,089 & $41.43 \%$ & & \\
\hline 1983 & 6 & 1.329 & 532,706 & 217,819 & $40.89 \%$ & & \\
\hline 1984 & 6 & 1.289 & 529,362 & 206,385 & $38.99 \%$ & & \\
\hline 1985 & 6 & 1.279 & 532,405 & 210,428 & $39.52 \%$ & & \\
\hline 1986 & 10 & 1.344 & 567,310 & 231,811 & $40.86 \%$ & $48.86 \%$ & $87.95 \%$ \\
\hline 1987 & 10 & 1.366 & 574,819 & 240,565 & $41.85 \%$ & $48.81 \%$ & $87.31 \%$ \\
\hline 1988 & 12 & 1.411 & 603,741 & 253,724 & $42.03 \%$ & $50.42 \%$ & $85.91 \%$ \\
\hline 1989 & $12 \backslash 15$ & 1.394 & 601,669 & 247,091 & $41.07 \%$ & $50.89 \%$ & $86.98 \%$ \\
\hline 1990 & $15 \backslash 18$ & 1.448 & 640,879 & 274,961 & $42.90 \%$ & $52.02 \%$ & $86.72 \%$ \\
\hline 1991 & 18 & 1.42 & 627,077 & 285,817 & $45.58 \%$ & $54.50 \%$ & $85.86 \%$ \\
\hline 1992 & $36(18)$ & 1.4 & 617,259 & 280,282 & $45.41 \%$ & $54.70 \%$ & $84.65 \%$ \\
\hline 1993 & $36(24)$ & 1.41 & 612,097 & 272,939 & $44.59 \%$ & $54.38 \%$ & $84.77 \%$ \\
\hline \multicolumn{8}{|c|}{ Panel B: Pre-birth Characteristics } \\
\hline 1 & 2 & 3 & 4 & 5 & 6 & 7 & 8 \\
\hline year & $\mathrm{ML}$ & low & medium & high & age & daily wage & part-time \\
\hline 1977 & 2 & 24.10 & 74.13 & 1.77 & 26.0 & 4.38 & $12.36 \%$ \\
\hline 1978 & 2 & 22.86 & 74.99 & 2.15 & 26.3 & 4.41 & $12.66 \%$ \\
\hline 1979 & 216 & 21.91 & 75.49 & 2.59 & 26.6 & 4.42 & $13.34 \%$ \\
\hline 1980 & 6 & 21.28 & 75.94 & 2.78 & 26.7 & 4.43 & $13.55 \%$ \\
\hline 1981 & 6 & 20.31 & 76.95 & 2.74 & 27.0 & 4.44 & $13.96 \%$ \\
\hline 1982 & 6 & 19.07 & 78.17 & 2.75 & 27.2 & 4.44 & $14.28 \%$ \\
\hline 1983 & 6 & 18.15 & 78.94 & 2.91 & 27.4 & 4.43 & $14.79 \%$ \\
\hline 1984 & 6 & 17.90 & 79.07 & 3.03 & 27.8 & 4.44 & $15.82 \%$ \\
\hline 1985 & 6 & 17.17 & 79.54 & 3.30 & 27.9 & 4.45 & $16.55 \%$ \\
\hline 1986 & 10 & 16.33 & 80.21 & 3.46 & 28.1 & 4.47 & $17.28 \%$ \\
\hline 1987 & 10 & 15.84 & 80.63 & 3.53 & 28.3 & 4.50 & $17.60 \%$ \\
\hline 1988 & 12 & 15.01 & 81.21 & 3.78 & 28.4 & 4.53 & $18.24 \%$ \\
\hline 1989 & $12 \backslash 15$ & 14.96 & 81.09 & 3.95 & 28.6 & 4.53 & $18.82 \%$ \\
\hline 1990 & $15 \backslash 18$ & 14.32 & 81.56 & 4.12 & 28.7 & 4.54 & $19.80 \%$ \\
\hline 1991 & 18 & 14.34 & 81.45 & 4.21 & 29.0 & 4.57 & $20.19 \%$ \\
\hline 1992 & $36(18)$ & 13.74 & 81.82 & 4.44 & 29.3 & 4.60 & $20.70 \%$ \\
\hline 1993 & $36(24)$ & 12.25 & 83.00 & 4.75 & 29.5 & 4.62 & $21.47 \%$ \\
\hline
\end{tabular}

Note: Panel A: Column 2: Length of job-protected maternity leave. Column 3: fertility rate (average number of children of women who are between 15 and 45 years old (Source: Statistisches Bundesamt)). Column 4: number of registered births of West-German women (Source: Statistisches Bundesamt). Column 5: Number of observations in final sample. Column 6: Ratio between number of observations and number of registered births. Column 7 and 8: Incidence of leave taking, source: German Pension Register, Sample 3. Panel B: Pre-birth characteristics are measured at 9 months prior to child birth. 
Figure 2: When Do Women Return to Work?

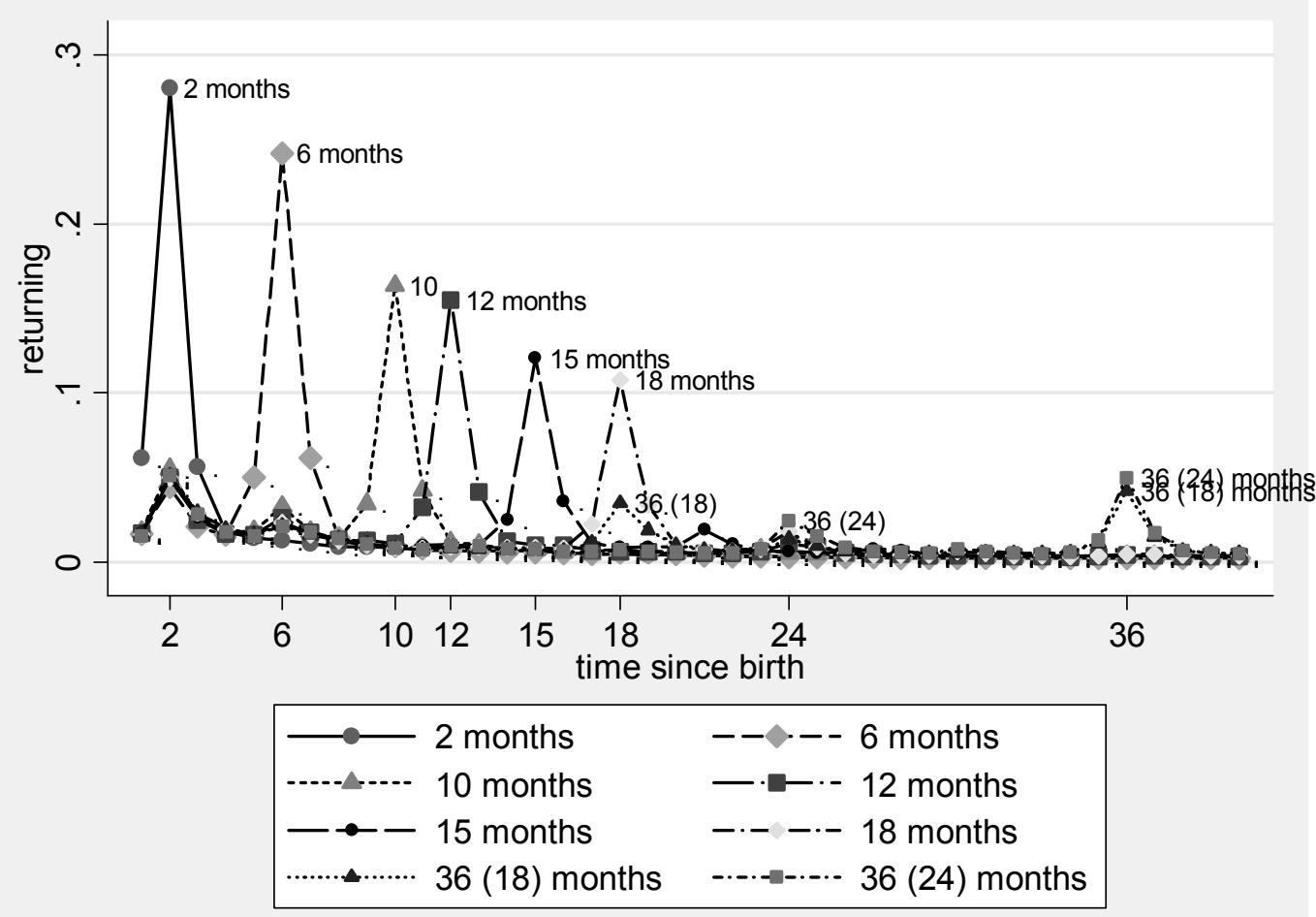

Note: The figure shows the fraction of women who return to work $t$ months after childbirth for 8 different maternity leave regimes. 2 months: birth between 3/76-3/79. 6 months: birth between 5-7912/85. 10 months: birth between 1/86 -12/87. 12 months: birth between 1/88-6/89. 15 months: birth between 7/89-6/90. 18 months: birth between 7/90-12/91. 36 (benefits 18) months: birth between 1/9212/92. 36 (benefits 24) months: birth between1/93-12/93. 
Figure 3a: Fraction of women returning by month 2, 6 or 10 after childbirth

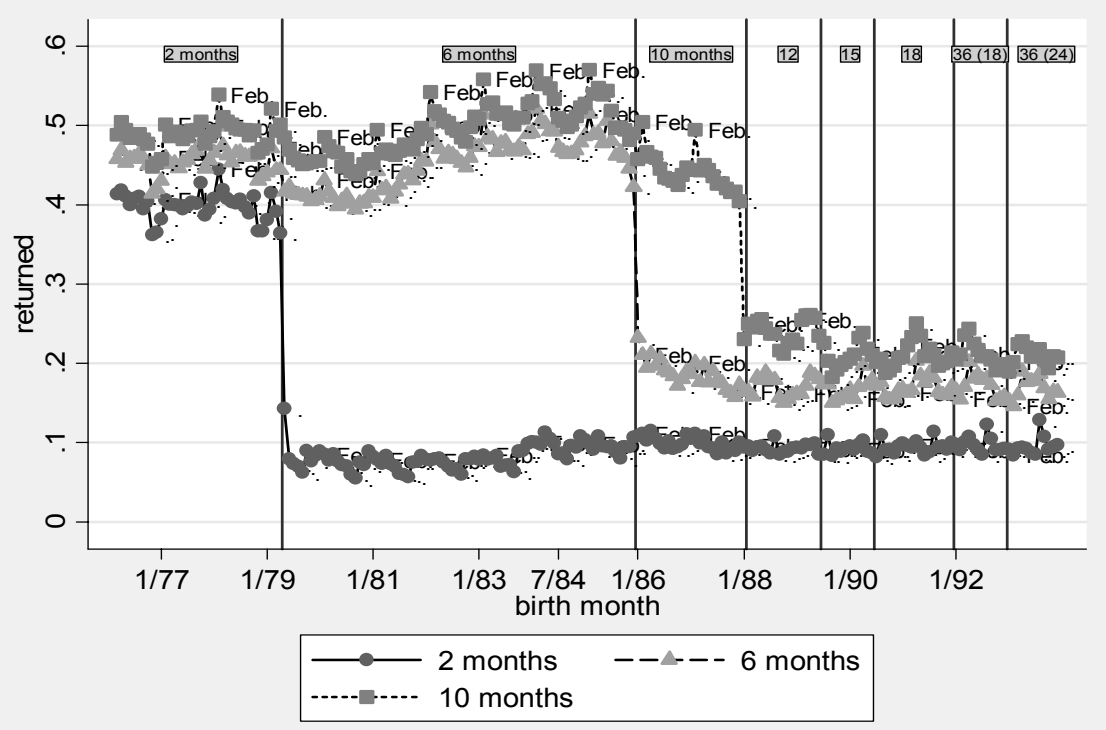

Figure 3b: Fraction of women returning by month 12, 15 or 18 after childbirth

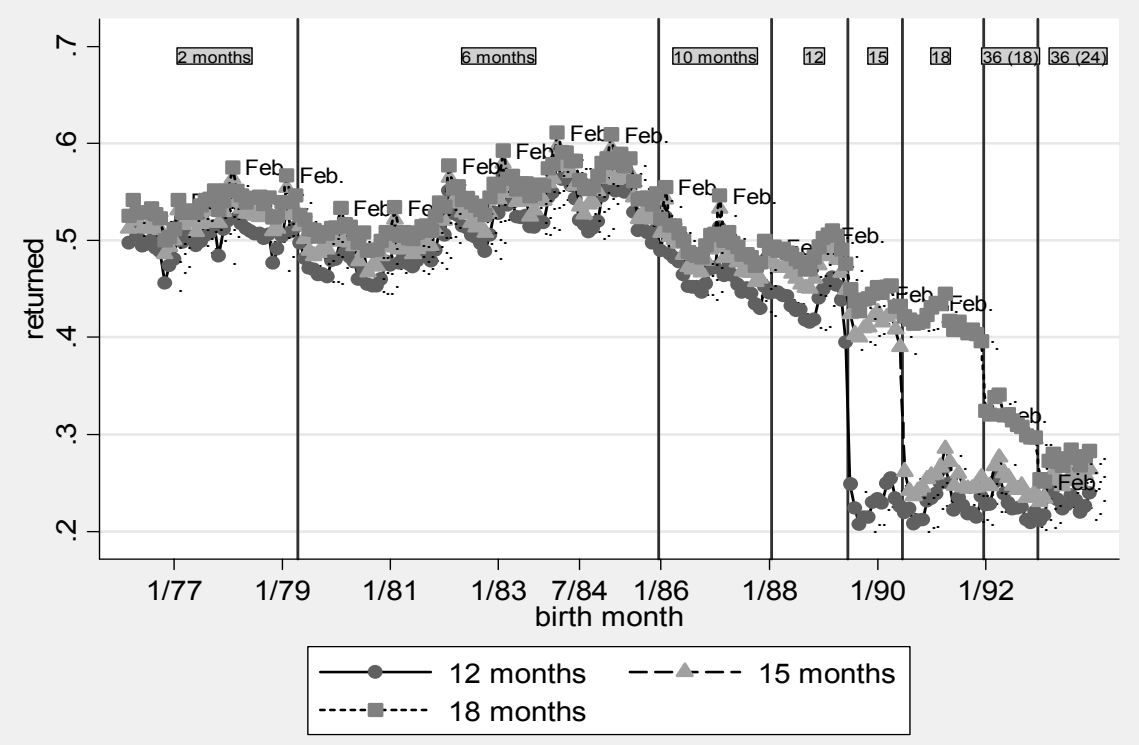

Note: The figures show the fraction of women who have returned to the labor market within $t$ months of childbirth. Vertical lines indicate a change in maternity leave legislation. 
Table 5: Maternity Leave Policy and Women's Return to Work Decision

\begin{tabular}{|c|c|c|c|c|c|c|c|}
\hline & \multicolumn{6}{|c|}{ 1st Reform: 2 versus 6 months (May 1979) } \\
\hline & & 2 & 12 & 24 & 36 & 60 & 96 \\
\hline & fraction returned, $3 / 79$ & $39.13 \%$ & $\overline{42.40 \%}$ & $\overline{56.09 \%}$ & $\overline{59.14 \%}$ & $63.66 \%$ & $67.15 \%$ \\
\hline 1 & April 79 vs May 79 & -0.221 & -0.016 & -0.012 & -0.010 & -0.008 & -0.006 \\
\hline 1 & & $(0.005)^{\star * *}$ & $(0.006)^{\star * *}$ & $(0.006)^{\star *}$ & $(0.006)^{*}$ & $(0.005)$ & $(0.005)$ \\
\hline 2 & April 79 vs May 79 , corrected & -0.320 & -0.023 & -0.017 & -0.015 & -0.011 & -0.009 \\
\hline \multirow[t]{2}{*}{3} & March 79 vs June 79 & -0.312 & -0.027 & -0.019 & -0.019 & -0.015 & -0.011 \\
\hline & & $(0.005)^{\star * *}$ & $(0.006)^{* * *}$ & $(0.006)^{* * *}$ & $(0.006)^{* \star *}$ & $(0.006)^{* *}$ & $(0.005)^{\star *}$ \\
\hline \multirow[t]{2}{*}{4} & March 79 vs June/July 79 & -0.315 & -0.032 & -0.023 & -0.022 & -0.019 & -0.015 \\
\hline & & $(0.004)^{* * *}$ & $(0.005)^{* * *}$ & $(0.005)^{* * *}$ & $(0.005)^{\star * *}$ & $(0.005)^{* * *}$ & $(0.005)^{* * *}$ \\
\hline \multirow[t]{5}{*}{5} & ly 79, DinD & -0.308 & -0.018 & -0.015 & -0.017 & -0.011 & -0.009 \\
\hline & : 1978) & $(0.005)^{* * *}$ & $(0.007)^{\star *}$ & $(0.007)^{\star *}$ & $(0.007)^{\star *}$ & $(0.007)$ & $(0.007)$ \\
\hline & & \multicolumn{6}{|c|}{ 2nd Reform: 6 versus 10 months (January 1986) } \\
\hline & & 6 & 10 & 18 & 30 & 66 & 90 \\
\hline & fraction returned, 11/85 & $44.59 \%$ & $48.19 \%$ & $53.73 \%$ & $57.67 \%$ & $66.79 \%$ & $70.58 \%$ \\
\hline \multirow[t]{2}{*}{1} & Dec. 85 vs Jan. 86 & -0.190 & -0.032 & -0.026 & -0.021 & -0.016 & -0.010 \\
\hline & & $(0.005)^{* * *}$ & $(0.005)^{* * *}$ & $(0.005)^{* * *}$ & $(0.005)^{\star * *}$ & $(0.005)^{* * *}$ & $(0.005)^{* *}$ \\
\hline 2 & Dec. 85 vs Jan. 86 , corrected & -0.275 & -0.046 & -0.038 & -0.031 & -0.024 & -0.014 \\
\hline \multirow[t]{2}{*}{3} & Nov. 85 vs March 86 & -0.252 & -0.015 & -0.021 & -0.011 & -0.002 & -0.006 \\
\hline & & $(0.005)^{\star * *}$ & $(0.005)^{\star * *}$ & $(0.005)^{* * *}$ & $(0.005)^{\star *}$ & $(0.005)$ & $(0.005)$ \\
\hline \multirow[t]{2}{*}{4} & Oct./Nov. 85 vs March 86 & -0.258 & -0.022 & -0.025 & -0.013 & -0.005 & -0.008 \\
\hline & & $(0.004)^{* * *}$ & $(0.005)^{\star \star *}$ & $(0.005)^{\star * *}$ & $(0.004)^{\star \star \star}$ & $(0.004)$ & $(0.004)^{*}$ \\
\hline \multirow[t]{5}{*}{5} & Oct./Nov. 85 vs March 86, DinD & -0.259 & -0.034 & -0.036 & -0.023 & -0.009 & -0.007 \\
\hline & & $(0.005)^{* * *}$ & $(0.006)^{* \star *}$ & $(0.006)^{* * *}$ & $(0.006)^{\star * *}$ & $(0.006)$ & $(0.006)$ \\
\hline & & \multicolumn{6}{|c|}{ 3rd Reform: 18 versus 36 months (January 1992) } \\
\hline & & 6 & 18 & 36 & 42 & 66 & 90 \\
\hline & fraction returned, 11/91 & $15.96 \%$ & $40.35 \%$ & $51.14 \%$ & $54.13 \%$ & $61.42 \%$ & $65.92 \%$ \\
\hline \multirow[t]{2}{*}{1} & Dec. 91 vs Jan. 92 & -0.004 & -0.072 & -0.021 & -0.018 & -0.011 & -0.007 \\
\hline & & $(0.003)$ & $(0.004)^{\star * *}$ & $(0.005)^{* * *}$ & $(0.005)^{\star * *}$ & $(0.004)^{\star *}$ & $(0.004)$ \\
\hline 2 & Dec. 91 vs Jan. & -0.006 & -0.104 & -0.031 & -0.026 & -0.016 & -0.011 \\
\hline \multirow[t]{2}{*}{3} & Nov. 91 vs March 92 & 0.011 & -0.065 & -0.014 & -0.011 & -0.007 & -0.001 \\
\hline & & $(0.003)^{* *}$ & $(0.005)^{\star \star *}$ & $(0.005)^{\star *}$ & $(0.005)^{\star *}$ & $(0.005)$ & $(0.004)$ \\
\hline \multirow[t]{2}{*}{4} & Oct./Nov. 91 vs March 92 & 0.011 & -0.067 & -0.016 & -0.011 & -0.008 & -0.001 \\
\hline & & $(0.003)^{* * *}$ & $(0.004)^{\star * *}$ & $(0.004)^{* * *}$ & $(0.004)^{* * *}$ & $(0.004)^{* *}$ & $(0.004)$ \\
\hline \multirow[t]{2}{*}{5} & Oct./Nov. 91 vs March 92, DinD & -0.001 & -0.086 & -0.025 & -0.023 & -0.018 & -0.012 \\
\hline & (control group: 1990/91) & $(0.003)$ & $(0.006)^{\star * *}$ & $(0.006)^{\star * *}$ & $(0.006)^{\star \star *}$ & $(0.005)^{\star * *}$ & $(0.005)^{*}$ \\
\hline
\end{tabular}

Note: The table reports estimates for the impact of the policy reform on the fraction of women who have returned to work within t months of childbirth. Row 2 corrects for measurement error by dividing the difference in the fraction of women who have returned to work one month before and one after after the change in legislation with the proportion of correct births, i.e. row 1/0.695. Row 5 uses women who give birth in the same months, but in a year in which there was no change in maternity leave legislation, as a control group. Robust standard errors in parentheses. *Statistically significant at 0.10 level, ${ }^{* *}$ at 0.05 level, ${ }^{* * *}$ at 0.01 level. 
Figure 4: Maternity Leave Policy and Women's Return Decision

Panel A: 2 versus 6 months (May 1979)

36 months after childbirth

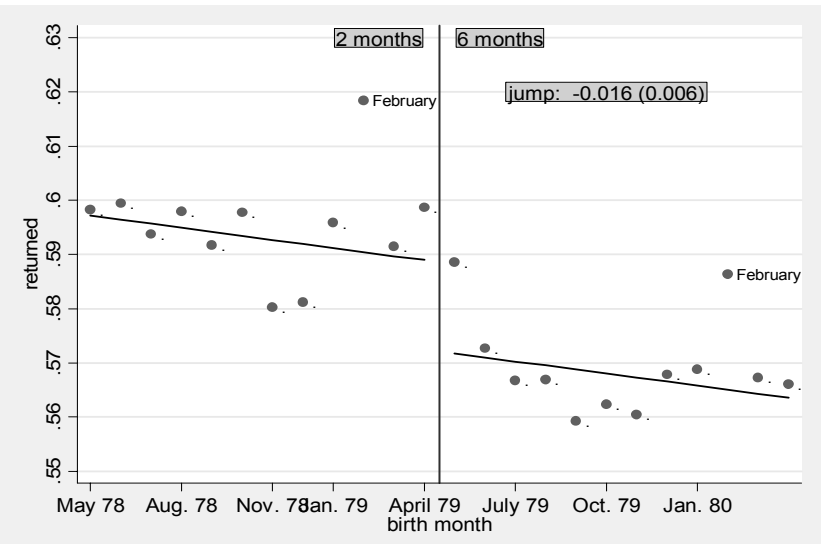

60 months after childbirth

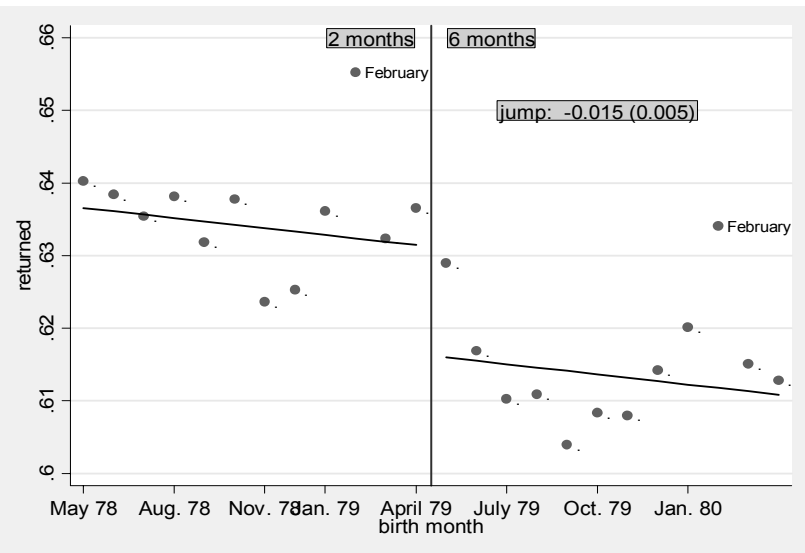

Panel B: 6 versus 10 months (January 1986)

30 months after childbirth

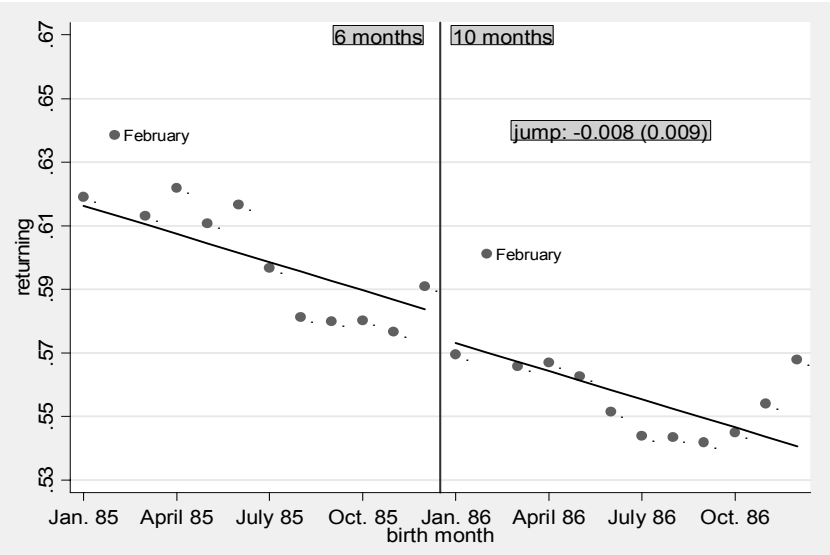

66 months after childbirth

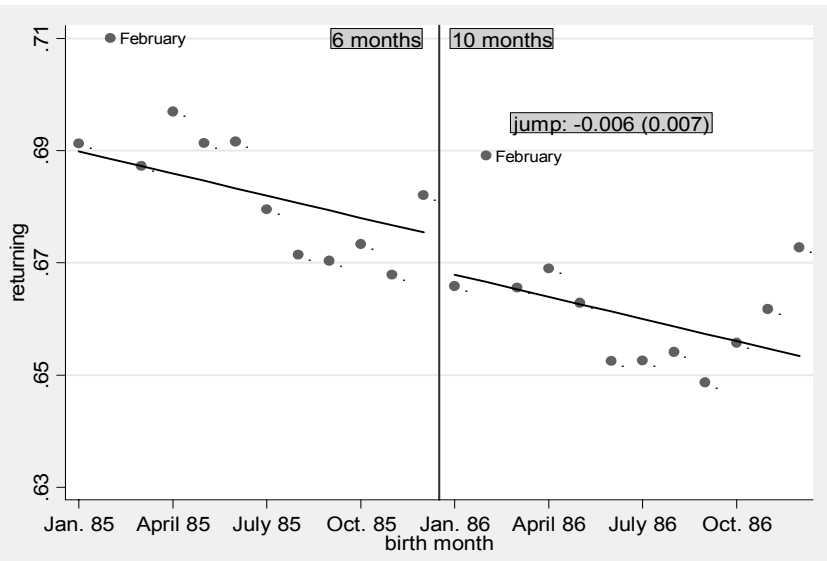

Panel C: 18 vs 36 months (January 1992)

36 months after childbirth

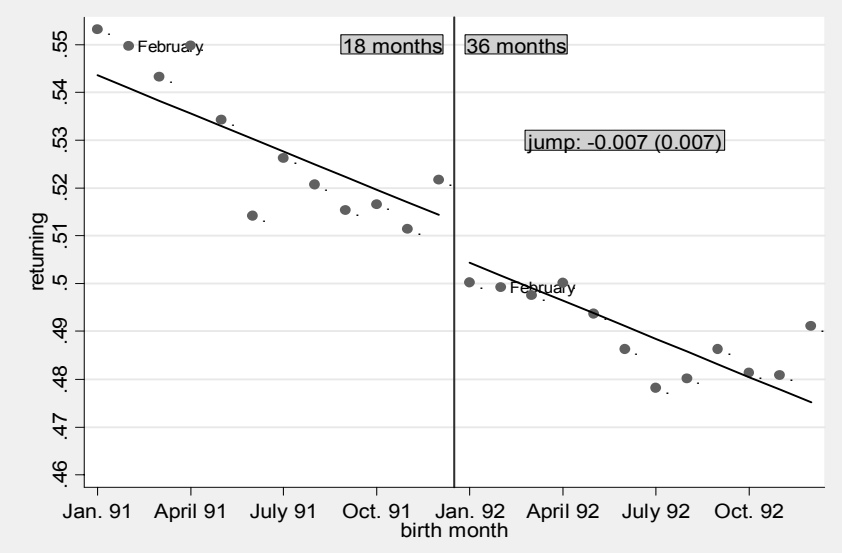

66 months after childbirth

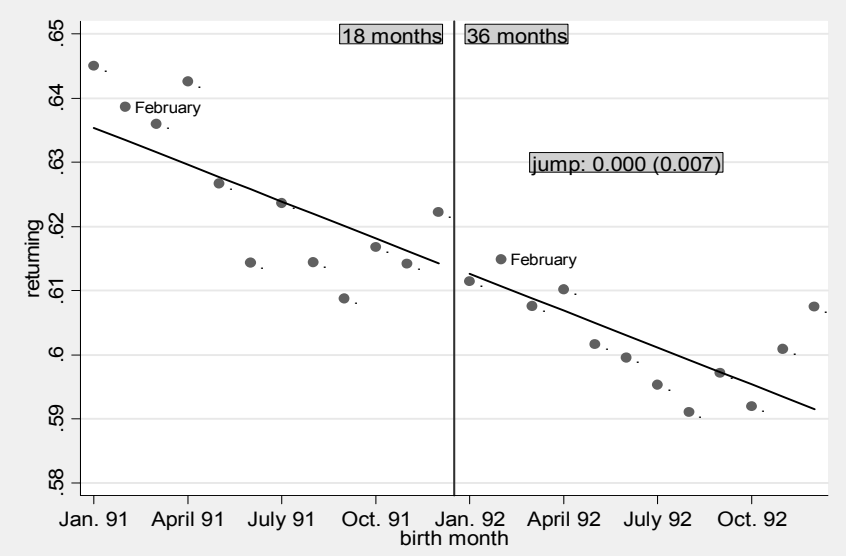

Note: The figure plots the fraction of women who have returned to work within t months after childbirth by birth month, for women who give birth one year before or after a change in maternity leave legislation. It also plots the predicted fraction, obtained from a linear regression that uses monthly data and controls for a linear time trend and a discontinuous jump when the law was changed ( $N=24)$. The figure in the box is the coefficient on the discontinuous jump. 
Table 6: Maternity Leave Policy and the Probability of Working after Childbirth

\begin{tabular}{|c|c|c|c|c|c|c|c|}
\hline & \multicolumn{6}{|c|}{ 1st Reform: 2 versus 6 months (May 1979) } \\
\hline & & 2 & 12 & 24 & 36 & 60 & 96 \\
\hline & fraction working, $3 / 79$ & $38.93 \%$ & $41.34 \%$ & $39.61 \%$ & $37.90 \%$ & $37.07 \%$ & $37.57 \%$ \\
\hline \multirow[t]{2}{*}{1} & April 79 vs May 79 & -0.221 & 0.005 & 0.003 & 0.000 & 0.002 & -0.001 \\
\hline & & $(0.005)^{\star \star \star}$ & $(0.006)$ & (0.006) & $(0.006)$ & $(0.005)$ & $(0.006)$ \\
\hline 2 & April 79 vs May 79, corrected & -0.320 & 0.007 & 0.005 & 0.000 & 0.003 & -0.002 \\
\hline \multirow[t]{2}{*}{3} & March 79 vs July 79 & -0.310 & 0.006 & 0.005 & 0.005 & 0.003 & 0.004 \\
\hline & & $(0.005)^{\star * *}$ & $(0.006)$ & $(0.006)$ & $(0.006)$ & $(0.006)$ & $(0.006)$ \\
\hline \multirow[t]{2}{*}{4} & March 79 vs June/July 79 & -0.313 & 0.004 & 0.007 & 0.005 & 0.003 & 0.002 \\
\hline & & $(0.004)^{* * *}$ & $(0.005)$ & $(0.005)$ & $(0.005)$ & $(0.005)$ & $(0.005)$ \\
\hline \multirow[t]{4}{*}{5} & March 79 vs June/July 79, DinD & -0.299 & 0.005 & 0.009 & 0.012 & 0.008 & 0.006 \\
\hline & (control group: 1978) & $(0.006)^{\star * *}$ & $(0.007)$ & $(0.007)$ & $(0.007)^{*}$ & $(0.007)$ & $(0.007)$ \\
\hline & & \multicolumn{6}{|c|}{ 2nd Reform: 6 versus 10 months (January 1986) } \\
\hline & & 6 & 10 & 18 & 30 & 66 & 90 \\
\hline & fraction working, $11 / 85$ & $44.43 \%$ & $46.07 \%$ & $45.05 \%$ & $42.52 \%$ & 43.95\% & $43.94 \%$ \\
\hline \multirow[t]{2}{*}{1} & Dec. 85 vs Jan. 86 & -0.189 & -0.023 & -0.007 & -0.003 & 0.003 & 0.004 \\
\hline & & $(0.005)^{\star * *}$ & $(0.005)^{\star * *}$ & 0.005 & $(0.005)$ & $(0.005)$ & $(0.005)$ \\
\hline 2 & Dec. 85 vs Jan. 86 , corrected & -0.274 & -0.033 & -0.010 & -0.005 & 0.004 & 0.006 \\
\hline \multirow[t]{2}{*}{3} & Nov. 85 vs March 86 & -0.253 & -0.002 & -0.004 & 0.008 & 0.008 & 0.007 \\
\hline & & $(0.005)^{\star * *}$ & $(0.005)$ & 0.005 & $(0.005)$ & $(0.005)$ & $(0.005)$ \\
\hline \multirow[t]{2}{*}{4} & Oct./Nov. 85 vs March 86 & -0.260 & -0.008 & -0.010 & 0.004 & 0.003 & 0.000 \\
\hline & & $(0.004)^{* * *}$ & $(0.004)^{*}$ & $(0.004)^{\star *}$ & $(0.004)$ & $(0.004)$ & $(0.004)$ \\
\hline \multirow[t]{4}{*}{5} & Oct./Nov. 85 vs & -0.260 & -0.019 & -0.018 & -0.003 & -0.001 & -0.004 \\
\hline & (control group: 1986/87) & $(0.005)^{* * *}$ & $(0.006)^{\star *}$ & $(0.006)^{* *}$ & $(0.006)$ & $(0.006)$ & $(0.006)$ \\
\hline & & \multicolumn{6}{|c|}{ 3rd Reform: 18 versus 36 months (January 1992) } \\
\hline & & 6 & 18 & 36 & 42 & 66 & 90 \\
\hline & fraction working, $11 / 91$ & $\overline{15.77 \%}$ & $37.25 \%$ & $37.69 \%$ & $37.95 \%$ & $40.37 \%$ & $39.88 \%$ \\
\hline \multirow[t]{2}{*}{1} & Dec. 91 vs Jan. 92 & -0.005 & -0.073 & 0.002 & 0.010 & 0.003 & 0.009 \\
\hline & & $(0.003)$ & $(0.004)^{\star * *}$ & 0.004 & $(0.004)^{\star *}$ & $(0.004)$ & $(0.004)^{* *}$ \\
\hline 2 & Dec. 91 vs Jan. 92, corrected & -0.007 & -0.106 & 0.003 & 0.014 & 0.004 & 0.013 \\
\hline \multirow[t]{2}{*}{3} & Nov. 91 vs March 92 & 0.006 & -0.090 & 0.015 & 0.025 & 0.011 & 0.022 \\
\hline & & $(0.003)$ & $(0.004)^{\star * *}$ & $(0.005)^{\star * *}$ & $(0.004)^{\star * *}$ & $(0.005)^{\star *}$ & $(0.005)^{* * *}$ \\
\hline \multirow[t]{2}{*}{4} & Oct./Nov. 91 vs March 92 & 0.006 & -0.091 & 0.013 & 0.025 & 0.011 & 0.025 \\
\hline & & $(0.003)^{* *}$ & $(0.004)^{* * *}$ & $(0.004)^{* * *}$ & $(0.004)^{* * *}$ & $(0.004)^{* * *}$ & $(0.004)^{* * *}$ \\
\hline \multirow[t]{2}{*}{5} & Oct./Nov. 91 vs March 92, DinD & -0.001 & -0.107 & 0.016 & 0.011 & -0.004 & 0.009 \\
\hline & (control groun. an/o & $(0.004)$ & $(0.005)^{\star * *}$ & $(0.006)^{\star *}$ & $(0.005)^{\star *}$ & $(0.006)$ & $(0.005)^{*}$ \\
\hline
\end{tabular}

Note: The table reports estimates for the impact of the policy reform on the fraction of women who are working $t$ months after childbirth. Row 2 corrects for measurement error by dividing the difference in the fraction of women working one month before and one after after the change in legislation with the proportion of correct births, i.e. row 1/0.695. Row 5 uses women who give birth in the same months, but in a year in which there was no change in maternity leave legislation, as a control group. Robust standard errors in parentheses. *Statistically significant at 0.10 level, ${ }^{* *}$ at 0.05 level, ${ }^{* * *}$ at 0.01 level. 
Figure 5: Maternity Leave Policy and The Probability of Working after Childbirth

Panel A: 2 versus 6 months (May 1979)

36 months after childbirth

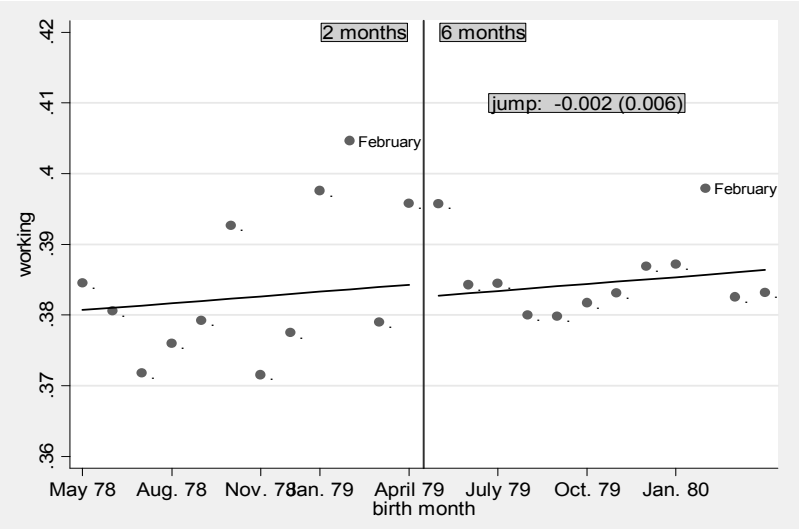

60 months after childbirth

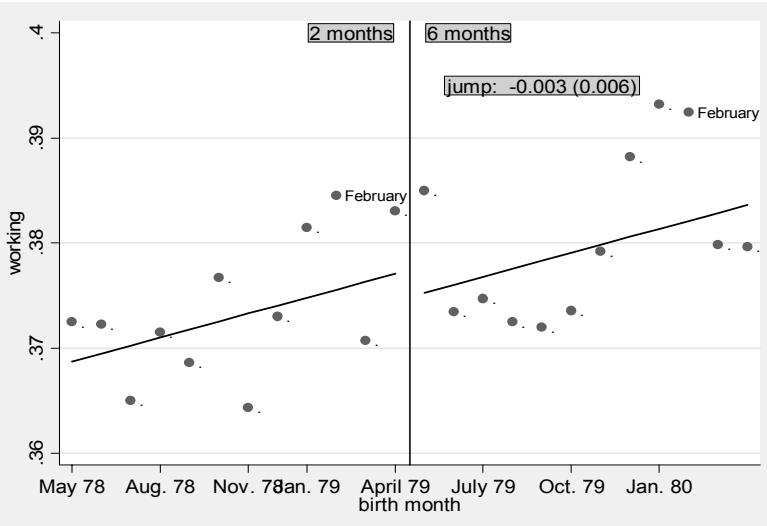

Panel B: 6 versus 10 months (January 1986)

30 months after childbirth

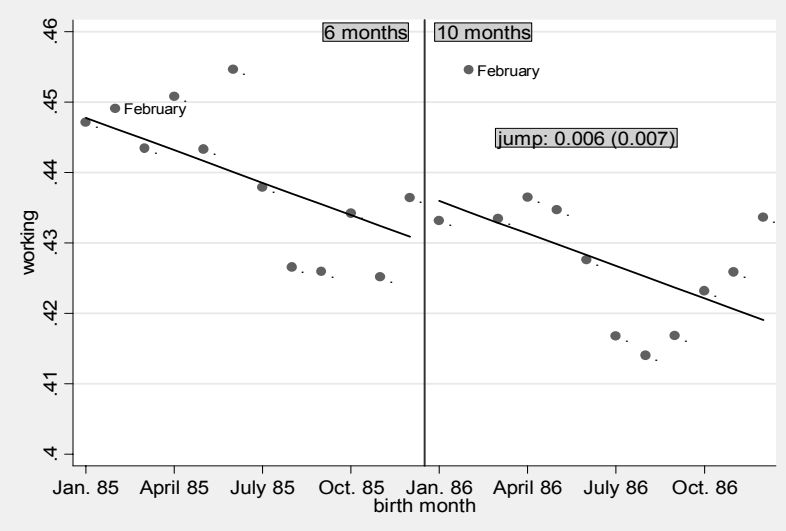

66 months after childbirth

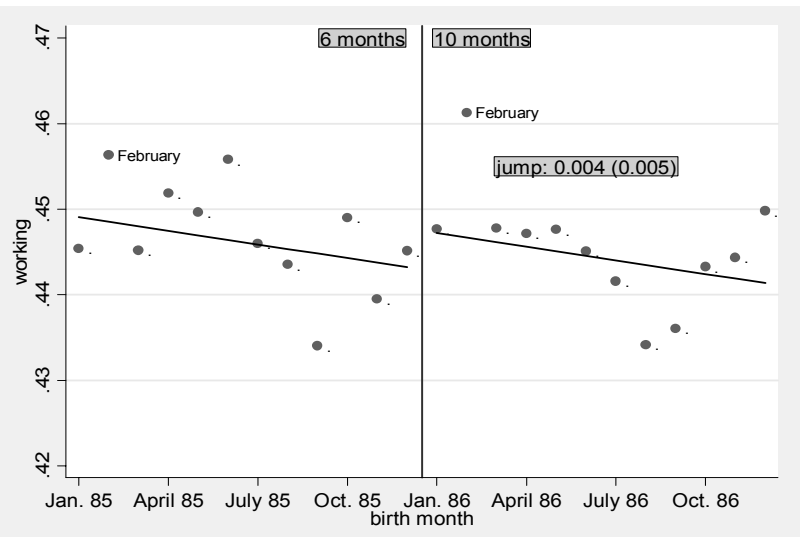

Panel C: 18 vs 36 months (January 1992)

36 months after childbirth

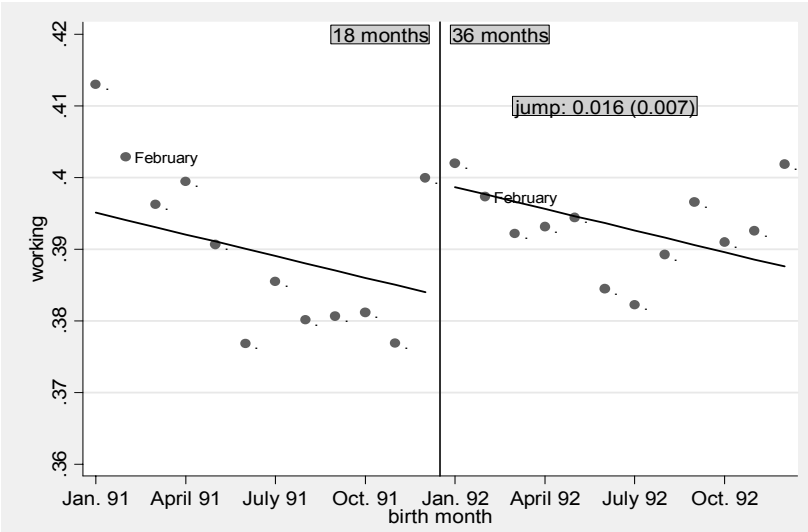

66 months after childbirth

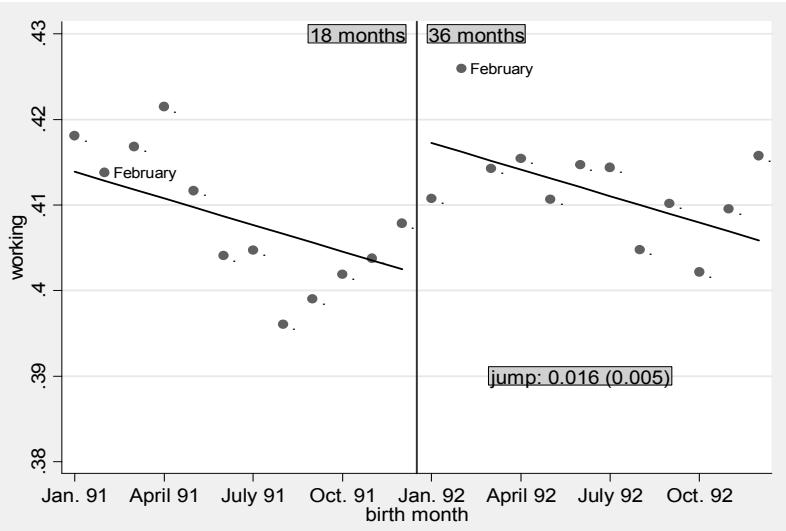

Note: The figure plots the fraction of women who are working $t$ months after childbirth by birth month, for women who give birth one year before or after a change in maternity leave legislation. It also plots the predicted fraction, obtained from a linear regression that uses monthly data and controls for a linear time trend and a discontinuous jump when the law was changed $(\mathrm{N}=24)$. The figure in the box is the coefficient on the discontinuous jump. 
Figure 6: Job Protection or Maternity Benefits?

Panel A: March 1979 versus June/July 1979

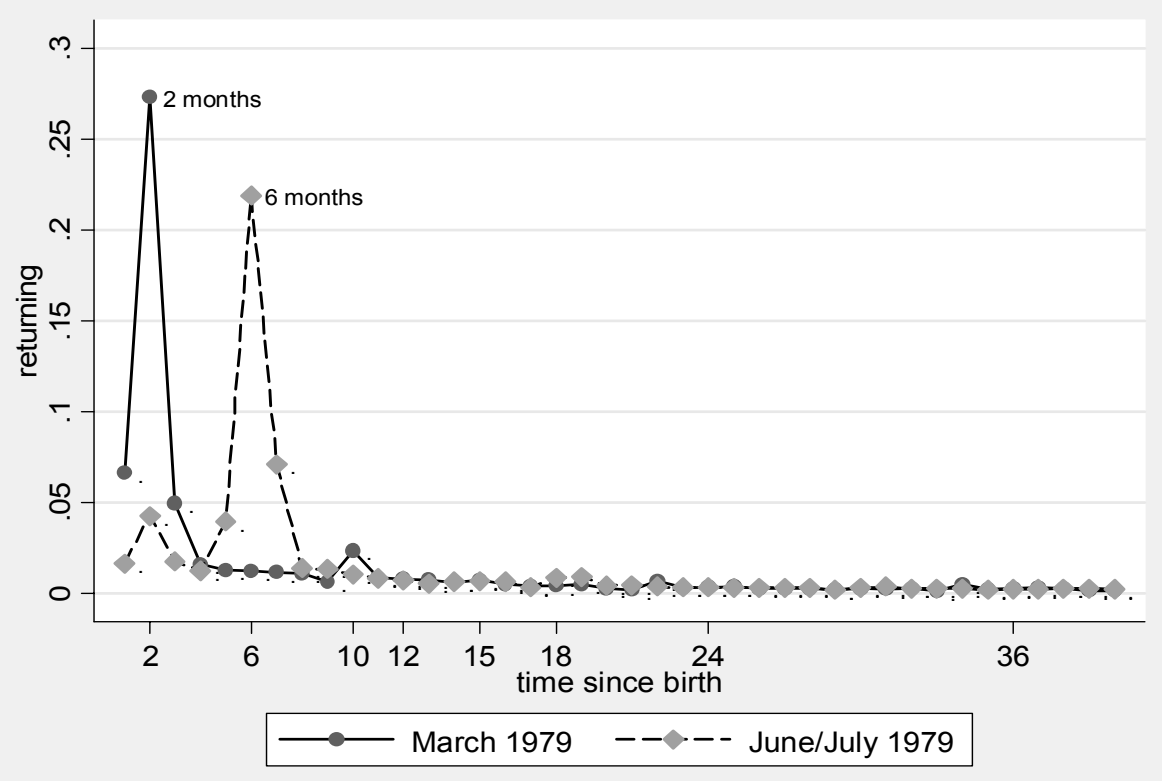

Panel B: October/November 1991 versus March 1992

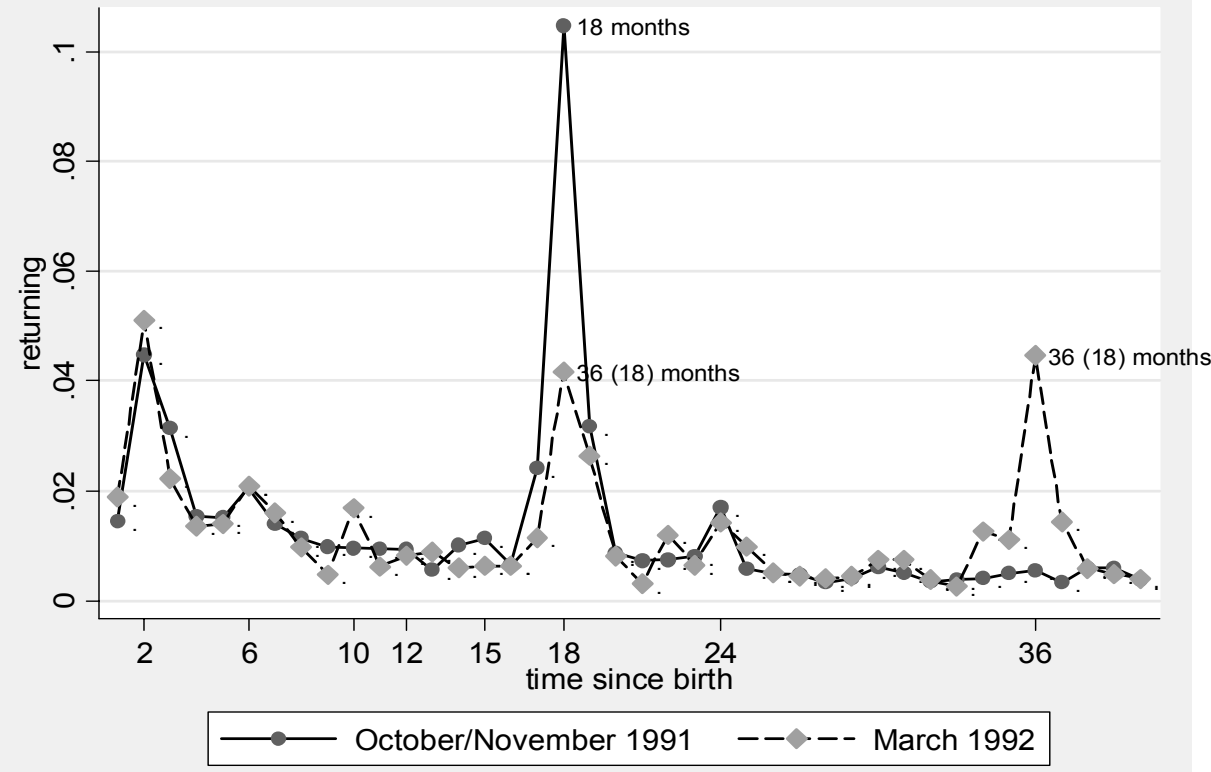

Note: The figure shows the fraction of women who return to work $t$ months after childbirth, and restricts the sample to women who give birth around a change in maternity leave legislation. Women who give birth in March 1979 are entitled to 2 months of fully paid leave. Women who give birth in June/July 1979 are entitled to 6 months of job-protected leave. Maternity benefits sharply drop from the 2 nd month (full payment) to the 3rd month (up to 375 Euros per month). Women who give birth in October/November 1991 are entitled to 18 months of job protection and maternity benefits (300 Euros per month). Women who give birth in March or October/November 1992 are entitled to 36 months of job protection and 18 months of maternity benefits (300 Euros per month). 
Table 7: Maternity Leave Policy and the Probability of Working for the Pre-Birth Employer

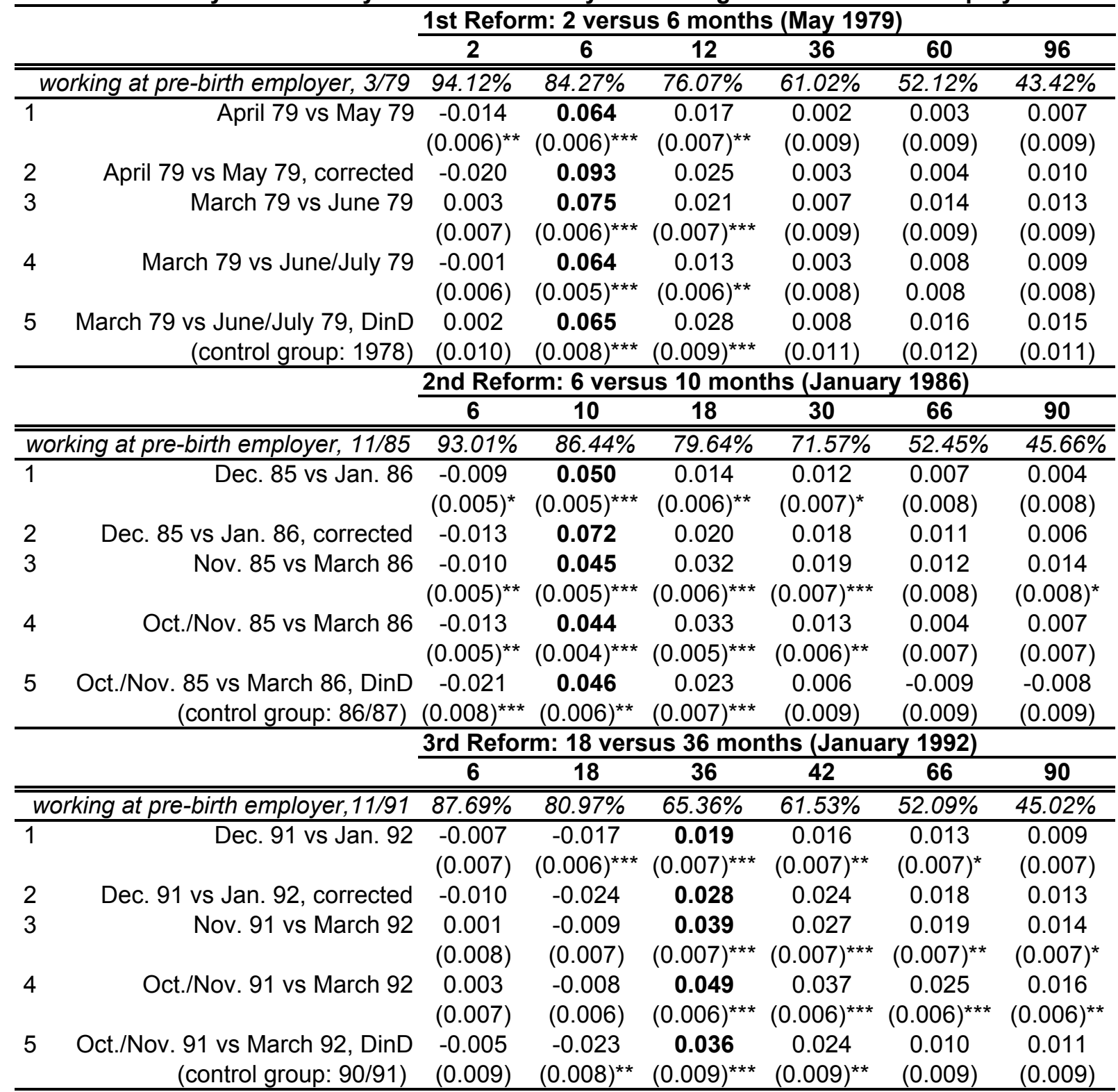

Note: The table reports estimates for the impact of the policy reform on the probability that a woman still works at her pre-birth employer $t$ months after childbirth (working women only). Row 2 corrects for measurement error by dividing the difference in the fraction of women working at the pre-birth employer one month before and one month after the change in legislation with the proportion of correct births, i.e. row 1/0.695. Row 5 uses women who give birth in the same months, but in a year in which there was no change in maternity leave legislation, as a control group. Robust standard errors in parentheses. *Statistically significant at 0.10 level, ${ }^{* *}$ at 0.05 level, ${ }^{* * *}$ at 0.01 level. 
Table 8: The impact of maternity leave legislation on daily wages

\begin{tabular}{|c|c|c|c|c|c|c|}
\hline & \multicolumn{5}{|c|}{ 1st Reform: 2 versus 6 months (May 1979) } \\
\hline & & 12 & 24 & 36 & 60 & 96 \\
\hline & daily log-wage, 3/79 & 4.282 & 4.259 & 4.239 & 4.250 & 4.324 \\
\hline \multirow[t]{2}{*}{1} & April 79 vs May 79 & 0.003 & -0.014 & -0.011 & -0.013 & -0.005 \\
\hline & & $(0.009)$ & $(0.009)$ & $(0.010)$ & $(0.010)$ & $(0.010)$ \\
\hline \multirow[t]{2}{*}{2} & March 79 vs July 79 & -0.016 & -0.026 & -0.027 & -0.028 & -0.020 \\
\hline & & $(0.009)^{*}$ & $(0.009)^{* * *}$ & $(0.010)^{* * *}$ & $(0.010)^{* * *}$ & $(0.010)^{* *}$ \\
\hline \multirow[t]{2}{*}{3} & March 79 vs June/July 79 & -0.009 & -0.014 & -0.022 & -0.025 & -0.019 \\
\hline & & $(0.008)$ & $(0.008)^{*}$ & $(0.009)^{* * *}$ & $(0.009)^{* * *}$ & $(0.009)^{\star *}$ \\
\hline \multirow[t]{2}{*}{4} & March 79 vs June/July 79 , DinD & -0.015 & -0.023 & -0.034 & -0.029 & -0.021 \\
\hline & (control group: 1980) & $(0.011)$ & $(0.011)^{* *}$ & $(0.012)^{* * *}$ & $(0.012)^{\star *}$ & $(0.011)^{*}$ \\
\hline \multirow[t]{2}{*}{5} & March/April 79 vs May-July 79 & -0.007 & -0.016 & -0.021 & -0.023 & -0.015 \\
\hline & & $(0.006)$ & $(0.006)^{* * *}$ & $(0.006)^{\star * *}$ & $(0.006)^{* * *}$ & $(0.006)^{\star *}$ \\
\hline \multirow[t]{5}{*}{6} & March/April 79 vs May-July 79, DinD & -0.009 & -0.016 & -0.025 & -0.021 & -0.011 \\
\hline & (control group: 1980) & $(0.008)$ & $(0.008)^{* *}$ & $(0.009)^{* * *}$ & $(0.009)^{\star *}$ & $(0.009)$ \\
\hline & & \multicolumn{5}{|c|}{ 2nd Reform: 6 versus 10 months (January 1986) } \\
\hline & & 18 & 30 & 42 & 66 & 90 \\
\hline & daily log-wage, 11/85 & 4.316 & 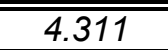 & 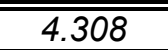 & 4.350 & 4.358 \\
\hline \multirow[t]{2}{*}{1} & Dec. 85 vs Jan. 86 & 0.010 & 0.002 & 0.000 & -0.004 & 0.001 \\
\hline & & $(0.009)$ & $(0.009)$ & $(0.009)$ & $(0.009)$ & $(0.009)$ \\
\hline \multirow[t]{2}{*}{2} & Nov. 85 vs March 86 & 0.013 & -0.003 & -0.001 & -0.006 & -0.002 \\
\hline & & $(0.009)$ & $(0.009)$ & $(0.009)$ & $(0.009)$ & $(0.009)$ \\
\hline \multirow[t]{2}{*}{3} & Oct./Nov. 85 vs March 86 & 0.009 & -0.005 & -0.010 & -0.008 & -0.011 \\
\hline & & $(0.007)$ & $(0.008)$ & $(0.008)$ & $(0.008)$ & $(0.007)$ \\
\hline \multirow[t]{2}{*}{4} & Oct./Nov. 85 vs March 86, DinD & 0.006 & -0.011 & -0.016 & -0.014 & -0.017 \\
\hline & (control group: 1986/87) & $(0.010)$ & $(0.011)$ & $(0.011)$ & $(0.011)$ & $(0.010)$ \\
\hline \multirow[t]{2}{*}{5} & Oct.-Dec. 85 vs Jan./March 86 & 0.011 & 0.001 & -0.005 & -0.005 & -0.005 \\
\hline & & $(0.005)^{\star *}$ & $(0.005)$ & $(0.006)$ & $(0.006)$ & $(0.006)$ \\
\hline \multirow[t]{5}{*}{6} & Oct.-Dec. 85 vs Jan./March 86, DinD & 0.008 & -0.003 & -0.010 & -0.007 & -0.009 \\
\hline & (control group: 1986/87) & $(0.008)$ & $(0.007)$ & $(0.008)$ & $(0.008)$ & $(0.008)$ \\
\hline & & \multicolumn{5}{|c|}{ 3rd Reform: 18 versus 36 months (January 1992) } \\
\hline & & 18 & 30 & 42 & 66 & 90 \\
\hline & daily log-wage, 11/91 & 4.280 & 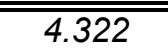 & 4.349 & 4.363 & 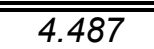 \\
\hline \multirow[t]{2}{*}{1} & Dec. 91 vs Jan. 92 & -0.001 & 0.029 & 0.011 & 0.013 & 0.003 \\
\hline & & $(0.010)$ & $(0.008)^{* * *}$ & $(0.008)$ & $(0.008)^{*}$ & $(0.006)$ \\
\hline \multirow[t]{2}{*}{2} & Nov. 91 vs March 92 & 0.004 & 0.019 & 0.006 & 0.005 & -0.012 \\
\hline & & $(0.011)$ & $(0.009)^{* *}$ & $(0.008)$ & $(0.008)$ & $(0.006)$ \\
\hline \multirow[t]{2}{*}{3} & Oct./Nov. 85 vs March 86 & 0.012 & 0.022 & 0.013 & 0.011 & -0.007 \\
\hline & & $(0.010)$ & $(0.008)^{\star * *}$ & $(0.007)^{*}$ & $(0.007)$ & $(0.005)$ \\
\hline \multirow[t]{2}{*}{4} & Oct./Nov. 91 vs March 92, DinD & -0.007 & 0.021 & 0.017 & 0.016 & -0.001 \\
\hline & (control group: 90/91) & $(0.013)$ & $(0.010)^{\star *}$ & $(0.010)^{*}$ & $(0.009)^{*}$ & $(0.008)$ \\
\hline \multirow[t]{2}{*}{5} & Oct.-Dec. 91 vs Jan./March 92 & 0.013 & 0.028 & 0.014 & 0.013 & -0.003 \\
\hline & & $(0.007)^{*}$ & $(0.006)^{* * *}$ & $(0.005)^{\star * *}$ & $(0.005)^{\star *}$ & $(0.004)$ \\
\hline \multirow[t]{2}{*}{6} & Oct.-Dec. 91 vs Jan./March 92, DinD & -0.006 & 0.025 & 0.015 & 0.009 & 0.000 \\
\hline & (control group: 90/91) & $(0.010)$ & $(0.008)^{* * *}$ & $(0.007)^{* *}$ & $(0.007)$ & $(0.006)$ \\
\hline
\end{tabular}

Note: The table reports estimates for the impact of the policy reform on the daily wage for those women who are working $t$ months after childbirth. Rows 4 and 6 uses women who give birth in the same months, but in a year in which there was no change in maternity leave legislation, as a control group. Robust standard errors in parentheses. * Statistically significant at 0.10 level, ${ }^{* *}$ at 0.05 level, ${ }^{* * *}$ at 0.01 level. 
Figure 7: Maternity Leave Policy and Wages

Panel A: 2 versus 6 months (May 1979)

\section{6 months after childbirth}

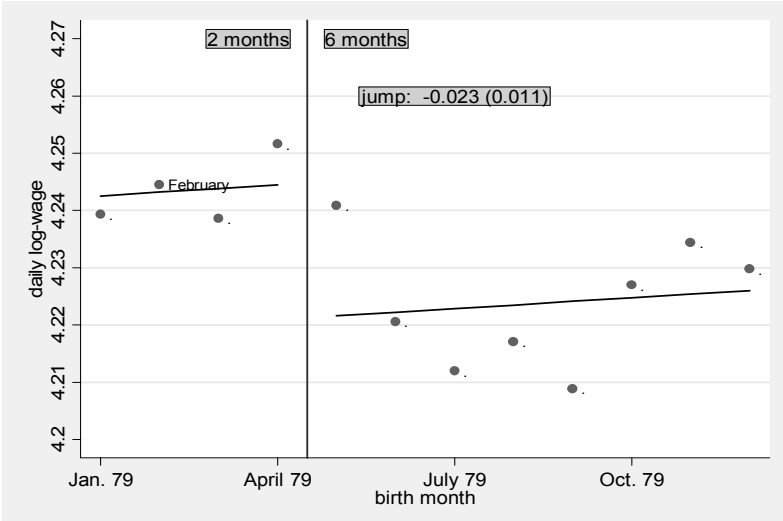

60 months after childbirth

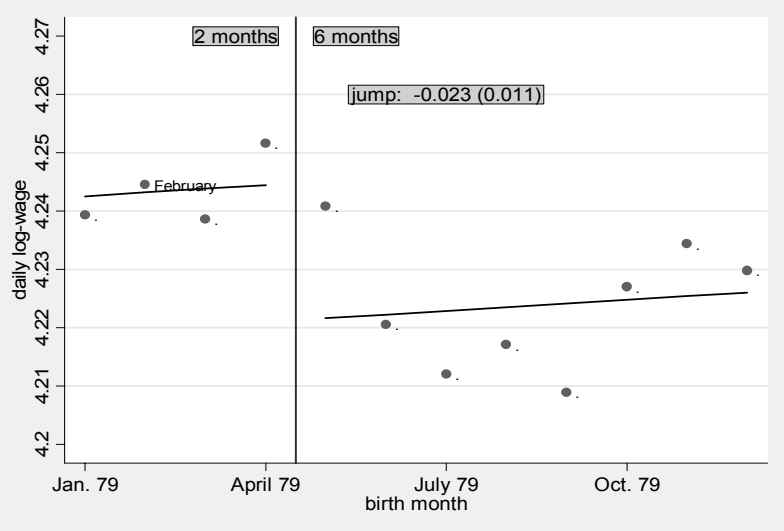

Panel B: 6 versus 10 months (January 1986)

30 months after childbirth

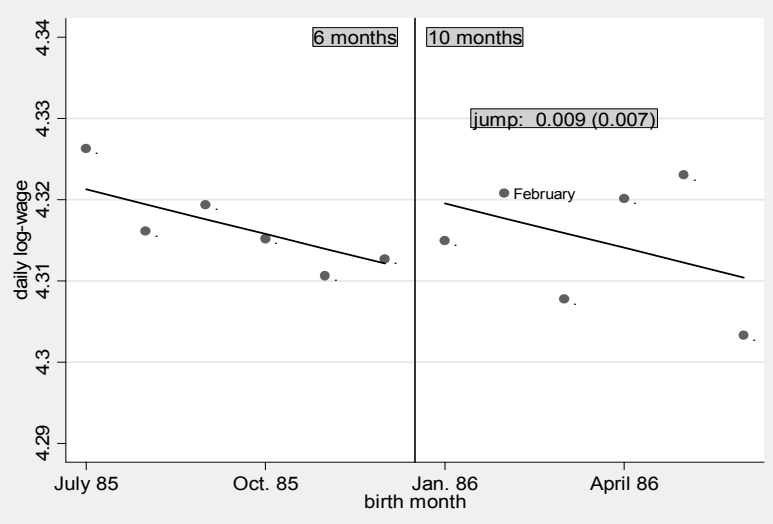

66 months after childbirth

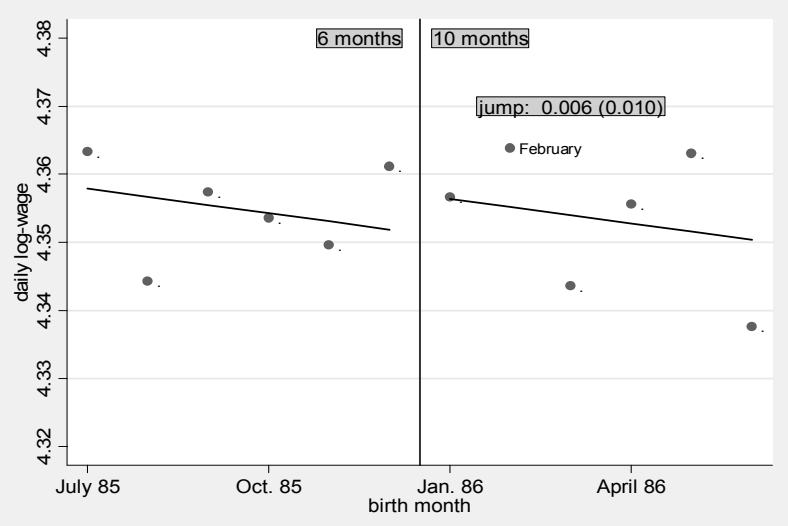

Panel C: 18 versus 36 months (January 1992)

42 months after childbirth

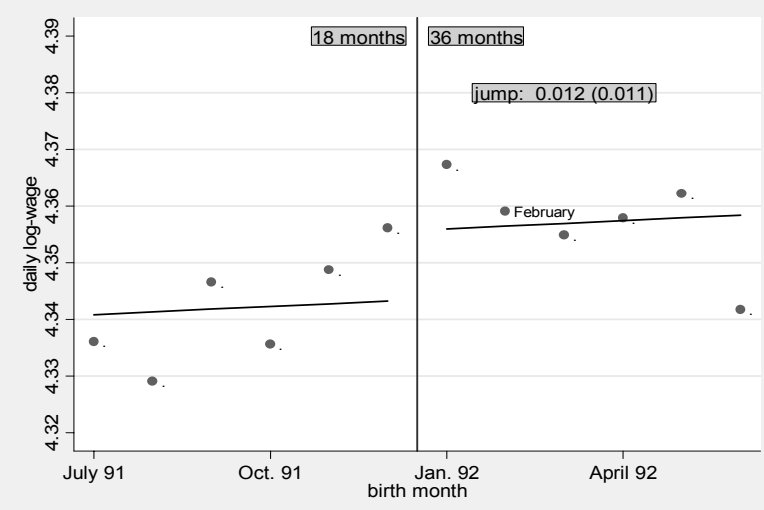

66 months after childbirth

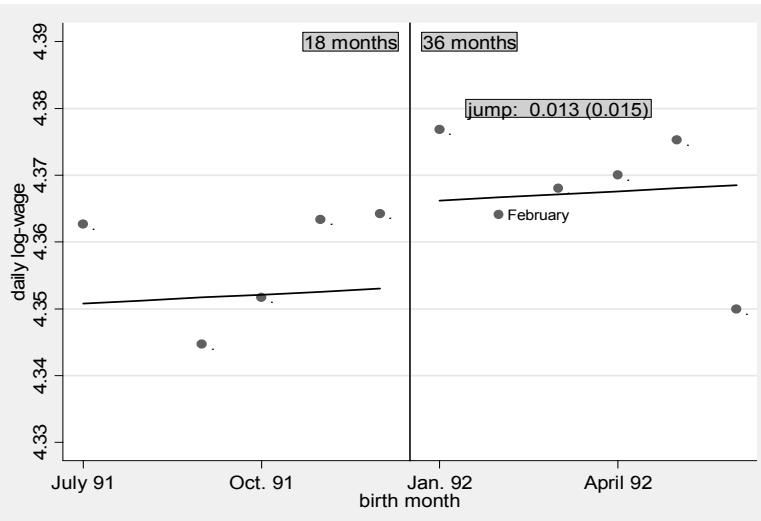

Note: The figure plots the average daily wage for women who are employed t months after childbirth by birth month, for women who give birth 6 months before or after a change in maternity leave legislation. It also plots the predicted fraction, obtained from a linear regression that uses monthly data and controls for a linear time trend and a discontinuous jump when the law was changed $(\mathrm{N}=12)$. The figure in the box is the coefficient on the discontinuous jump. 
Table 9: Maternity Leave Policy and Earnings: Channels

\begin{tabular}{|c|c|c|c|c|c|}
\hline & \multicolumn{5}{|c|}{ 1st Reform: 2 versus 6 months (May 1979) } \\
\hline & $\Delta \exp$ & $\triangle \mathrm{SE}$ & $\Delta \mathrm{FT}$ & Total & Selection \\
\hline \multicolumn{6}{|l|}{3 years after } \\
\hline diff. in char. & -1.306 & -0.002 & -0.005 & -0.021 & \\
\hline \multirow{4}{*}{ explanatory power (1) } & -0.018 & 0.000 & -0.002 & -0.019 & -0.002 \\
\hline & $(0.002)^{* * *}$ & $(0.000)$ & $(0.002)$ & $(0.003)^{* * *}$ & $(0.006)$ \\
\hline & -0.013 & 0.000 & -0.002 & -0.015 & -0.006 \\
\hline & $(0.001)^{* * *}$ & $(0.000)$ & $(0.002)$ & $(0.003)^{* * *}$ & $(0.006)$ \\
\hline \multicolumn{6}{|l|}{5 years after } \\
\hline diff. in char. & -1.192 & -0.003 & -0.005 & -0.023 & \\
\hline \multirow[t]{6}{*}{ explanatory power (1) } & -0.010 & 0.000 & -0.002 & -0.011 & -0.012 \\
\hline & $(0.001)^{\star \star *}$ & 0.000 & $(0.002)$ & $(0.003)^{\star * *}$ & $(0.006)^{*}$ \\
\hline & -0.009 & 0.000 & -0.002 & -0.011 & -0.012 \\
\hline & $(0.001)^{* * *}$ & $(0.000)$ & $(0.002)$ & $(0.003)^{\star * *}$ & $(0.006)^{*}$ \\
\hline & \multicolumn{5}{|c|}{ 2nd Reform: 6 versus 10 months (January 1986) } \\
\hline & 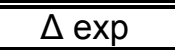 & $\triangle \mathrm{SSE}$ & $\overline{\Delta \mathrm{FT}}$ & Total & Selection \\
\hline \multicolumn{6}{|l|}{42 months after } \\
\hline diff. in char. & -0.015 & 0.004 & -0.008 & -0.005 & \\
\hline \multirow[t]{4}{*}{ explanatory power (1) } & -0.014 & 0.000 & -0.003 & -0.017 & 0.012 \\
\hline & $(0.001)^{\star * *}$ & $(0.001)$ & (0.002) & $(0.003)^{\star * *}$ & $(0.005)^{* *}$ \\
\hline & -0.013 & 0.000 & -0.003 & -0.016 & 0.011 \\
\hline & $(0.001)^{* * *}$ & $(0.000)$ & $(0.002)$ & $(0.002)^{* * *}$ & $(0.005)^{* *}$ \\
\hline
\end{tabular}

66 months after

\begin{tabular}{|c|c|c|c|c|c|c|}
\hline diff. in c & nar. & -1.109 & 0.005 & -0.012 & -0.005 & \\
\hline \multirow[t]{4}{*}{ explanatory power } & (1) & -0.008 & 0.000 & -0.004 & -0.012 & 0.007 \\
\hline & & $(0.001)^{\star * *}$ & $(0.000)$ & $(0.002)$ & $(0.002)^{\star * *}$ & (0.005) \\
\hline & (2) & -0.008 & 0.000 & -0.004 & -0.012 & 0.007 \\
\hline & & $(0.001)^{\star * *}$ & $(0.000)$ & $(0.002)$ & $(0.002)^{\star * *}$ & $(0.005)$ \\
\hline
\end{tabular}

\begin{tabular}{|c|c|c|c|c|c|}
\hline & \multicolumn{5}{|c|}{ 3rd Reform: 18 versus 36 months (January 1992) } \\
\hline & $\Delta \exp$ & $\Delta \mathrm{SE}$ & $\Delta \mathrm{FT}$ & Total & Selection \\
\hline \multicolumn{6}{|l|}{42 months after } \\
\hline diff. in char. & -2.257 & 0.022 & -0.003 & 0.014 & \\
\hline \multirow[t]{4}{*}{ explanatory power (1) } & -0.028 & 0.002 & -0.001 & -0.028 & 0.042 \\
\hline & $(0.002)^{\star \star \star}$ & $(0.000)^{\star * *}$ & $(0.002)$ & $(0.002)^{* * *}$ & $(0.005)^{\star \star *}$ \\
\hline & -0.024 & 0.002 & -0.001 & -0.023 & 0.037 \\
\hline & $(0.001)^{\star \star *}$ & $(0.000)^{\star * *}$ & $(0.001)$ & $(0.002)^{\star * *}$ & $(0.005)^{\star \star *}$ \\
\hline
\end{tabular}

66 months after

\begin{tabular}{|c|c|c|c|c|c|c|}
\hline \multirow{2}{*}{ diff. in cha } & & -1.669 & 0.014 & -0.008 & 0.013 & \\
\hline & \multirow[t]{2}{*}{ (1) } & -0.012 & 0.001 & -0.001 & -0.013 & 0.025 \\
\hline & & $(0.002)^{* * *}$ & $(0.000)^{\star * *}$ & (0.001) & $(0.002)^{* * *}$ & $(0.005)^{* * *}$ \\
\hline \multirow{2}{*}{\multicolumn{2}{|c|}{ (2) }} & -0.013 & 0.001 & -0.001 & -0.013 & 0.025 \\
\hline & & $(0.002)^{\star * *}$ & $(0.000)^{* * *}$ & (0.001) & $(0.002)^{* * *}$ & $(0.005)^{\star}$ \\
\hline
\end{tabular}

Note: The first row (diff. in char.) shows the difference in the number of months worked ( $\Delta$ exp), in the share working for the pre-birth employer $(\Delta \mathrm{SE})$, the share working full-time $(\Delta \mathrm{FT})$, as well as in the daily wage (total) between women who give birth before and after a change in maternity leave legislation (after-before). Row (1) reports to what extent each component can explain the total difference in wages, evaluated at after - prices. Selection refers to the unexplained component. Row (2) reverses the order of the decomposition, and evaluates each component at the before - prices. Results are based on women who give birth 3 months before or after the change in law, and exclude women who give birth in January. 
Table A:1: Measurement of wages: An example

Panel A: The 1986 policy reform

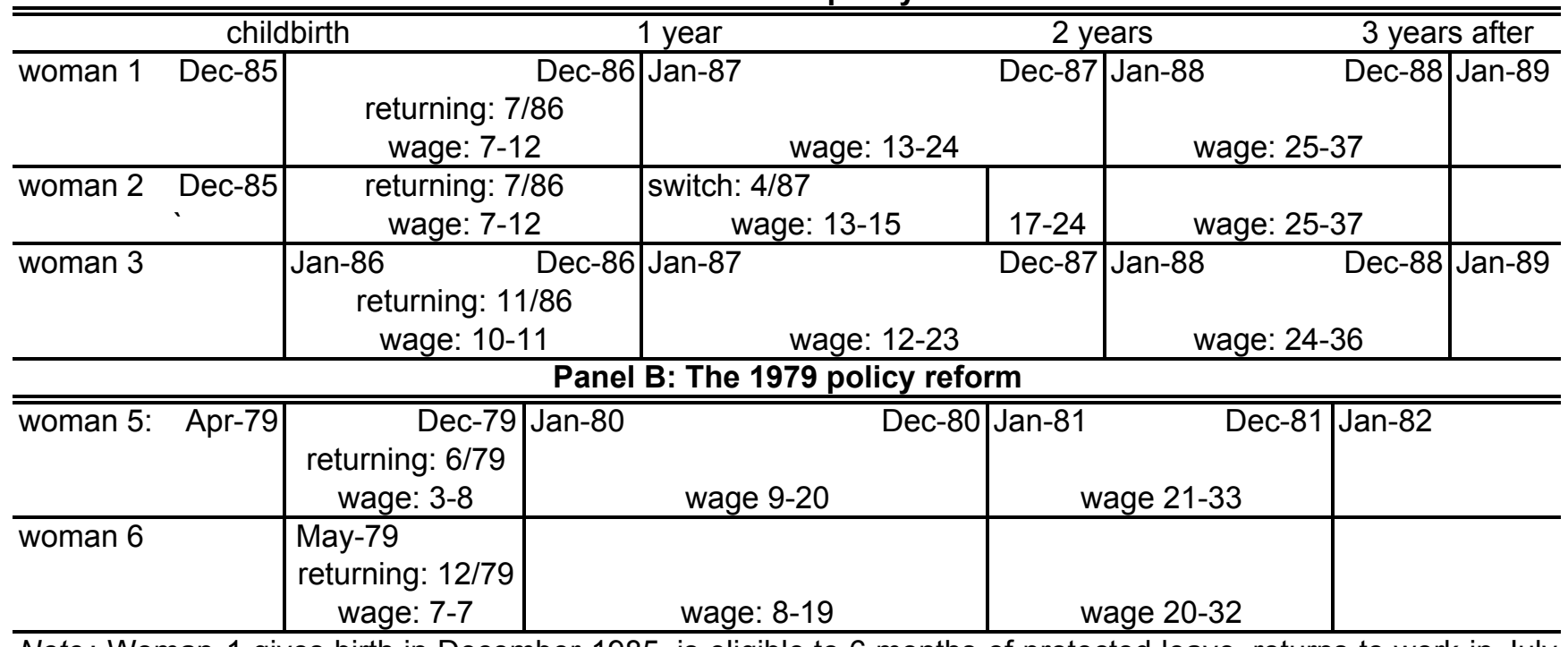

Note: Woman 1 gives birth in December 1985, is eligible to 6 months of protected leave, returns to work in July 1986, and keeps working for the same employer for the next three years. Woman 2 gives birth in December 1985, returns to work in July 1985, and switches firms in April 1987. Woman 3 gives birth in January 1986, is eligible to 10 months of protected leave, returns to work in November 1986, and keeps working for the same employer for the next three years. Woman 5 gives birth in April 1979, is eligible to 2 months of protected leave, returns to work in June 1979, and keeps working for the same employer for the next three years. Woman 5 gives birth in May 1979, is eligible to 6 months of protected leave, returns to work in December 1979, and keeps working for the same employer for the next 3 years. 
Figure B.1: Maternity Leaave Policy and the Incidence of Leave Taking

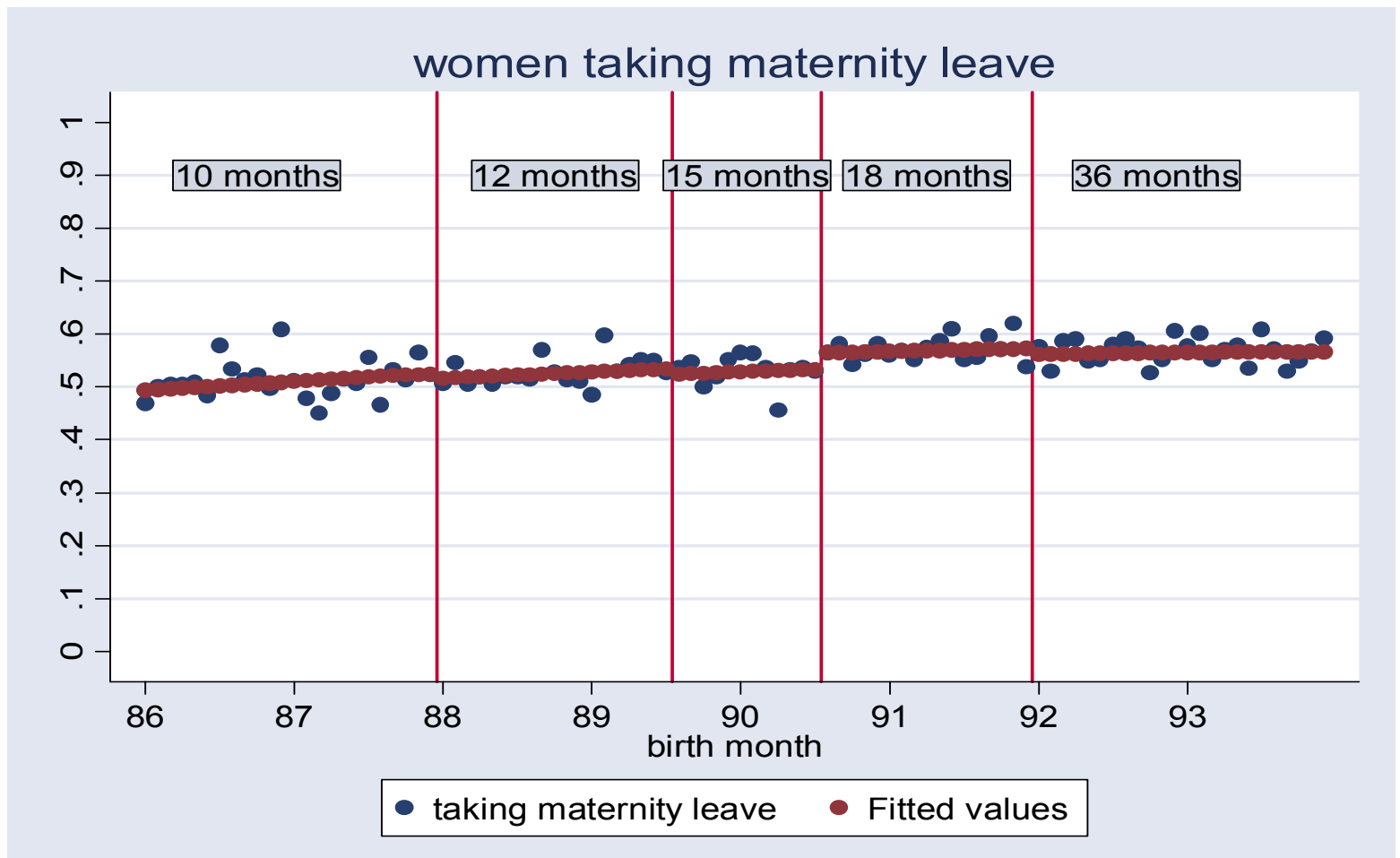

Note: Dots refer to the fraction of women taking maternity leave each month. The solid line are predicted averages fitting a quardratic time trend. Vertical lines indicate a change in the leave policy.

Table B1: Did the extensions in maternity leave legislation increase leave taking?

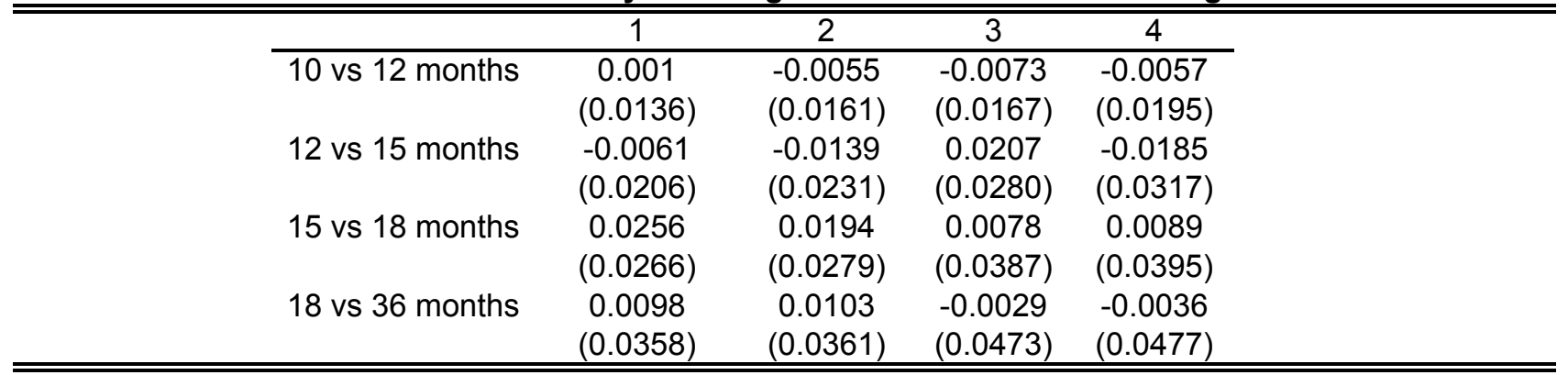

Note: German Pension Register, sample 1. $\mathrm{N}=14023$ (around 150 observations per month). Dependent variable: 1 if women takes maternity leave, 0 otherwise. Linear probability models. Column 1 controls for a linear time trend, column 2 for a quadratic time trend, column 3 for triple time trend, and column 4 for a quartic time trend. Each regression allows for a separate discontinuous jump whenever maternity leave was 


\section{Appendix C: Additional Results}

Figure C.1: Maternity Leave Policy and the Probability of Working at the Pre-Birth Employer Panel A: 2 versus 6 months (May 1979)

6 months after childbirth

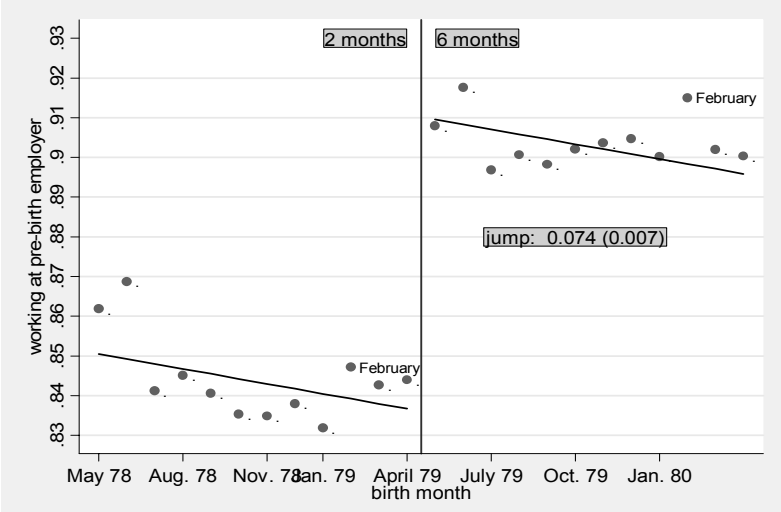

36 months after childbirth

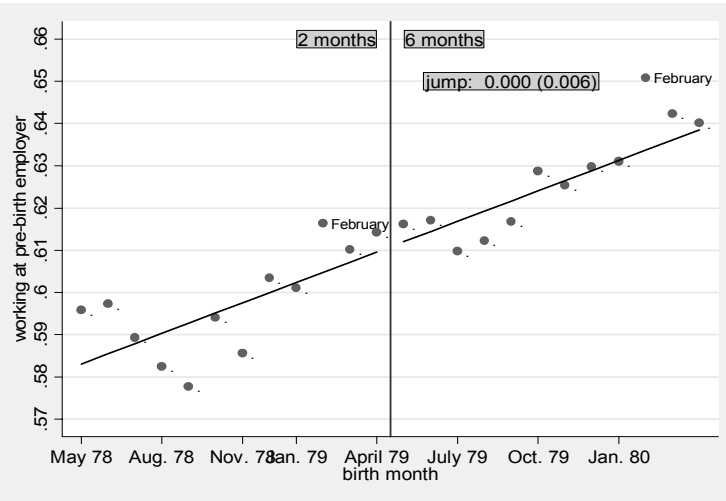

Panel B: 6 verus 10 months

10 months after childbirth

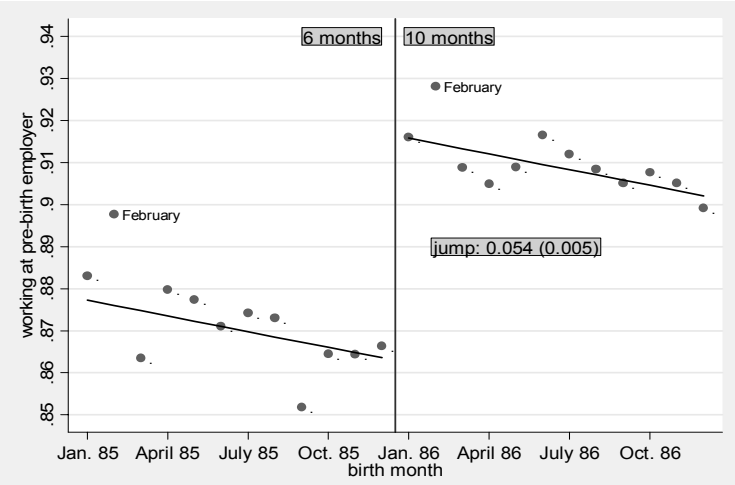

30 months after childbirth

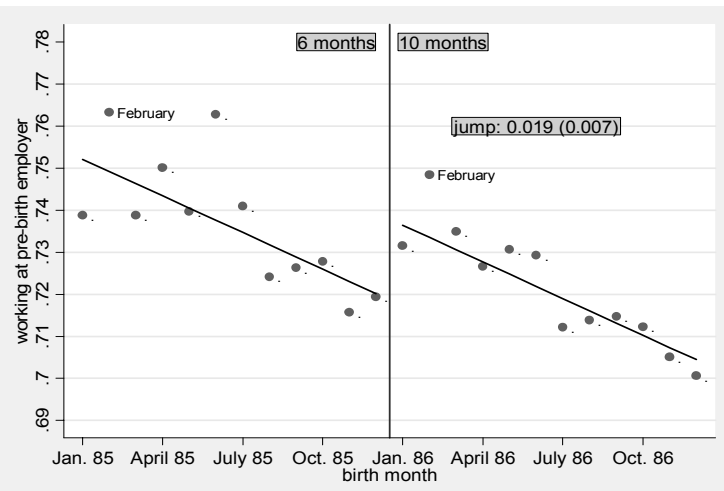

36 months after childbirth

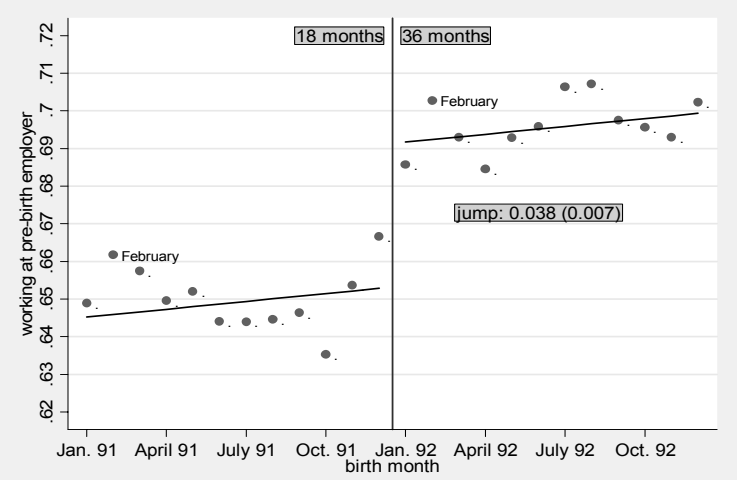

66 months after childbirth

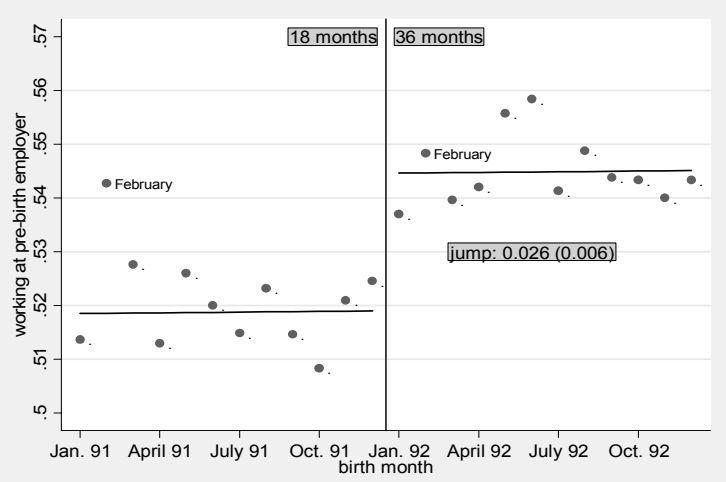

Note: The figure plots the fraction of women who are employed t months after childbirth and are working at their pre-birth employer by birth month, for women who give birth one year before or after a change in maternity leave legislation. It also plots the predicted fraction, obtained from a linear regression that uses monthly data and controls for a linear time trend and a discontinuous jump when the law was changed $(\mathrm{N}=24)$. The figure in the box is the coefficient on the discontinuous jump. 
Figure C2: Placebo Test (No Change in Maternity Leave Legislation)

Panel A: 2 versus 6 months: January - December 1980

36 months after childbirth

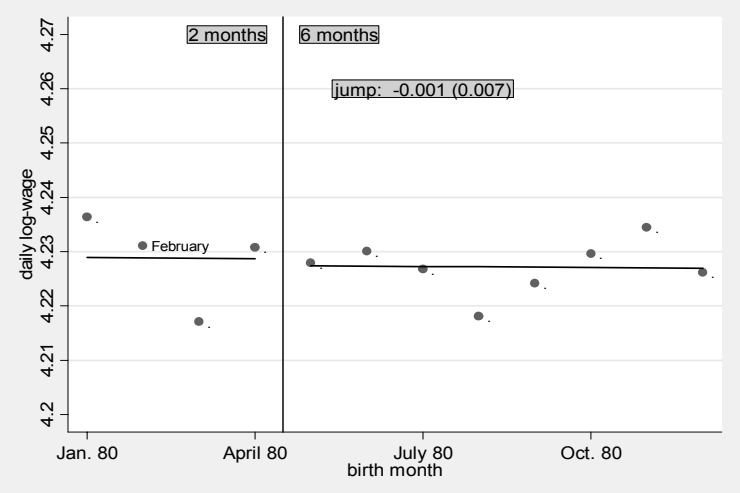

\section{0 months after childbirth}

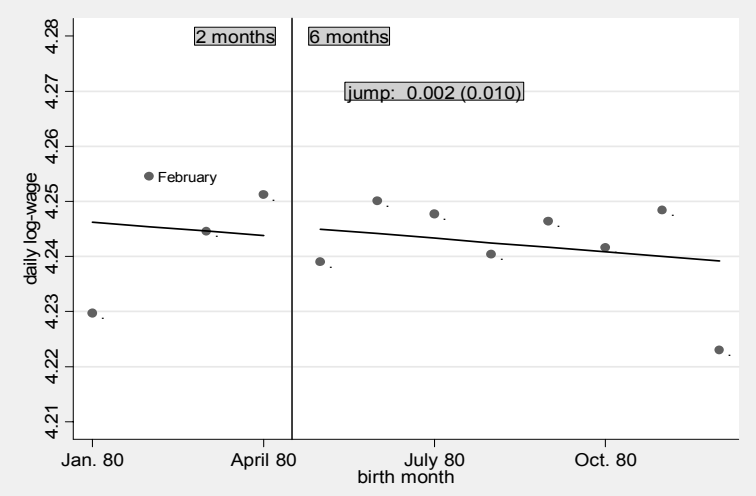

Panel B: 6 versus 10 months (July 1986-June 1987)

30 months after childbirth

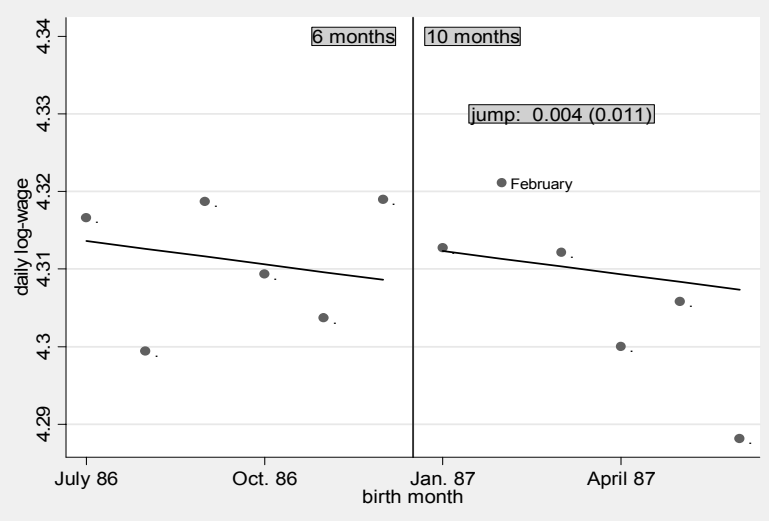

66 months after childbirth

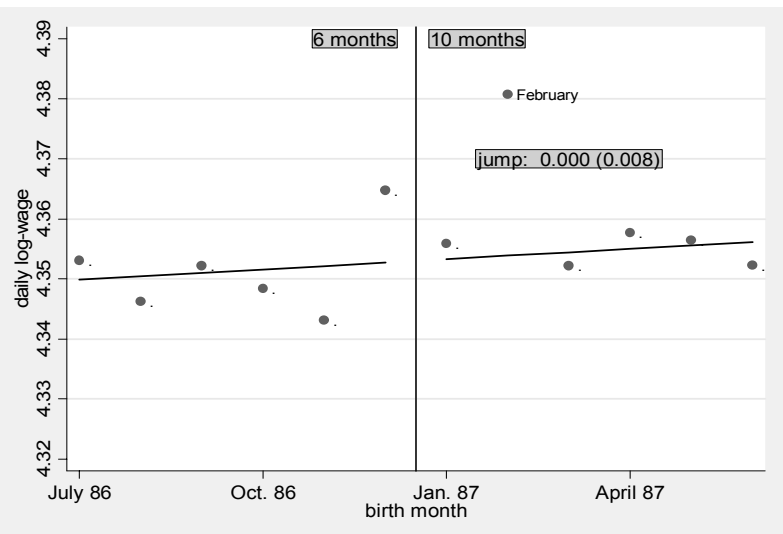

Panel C: 18 versus 36 months (July 1990-June 1991)
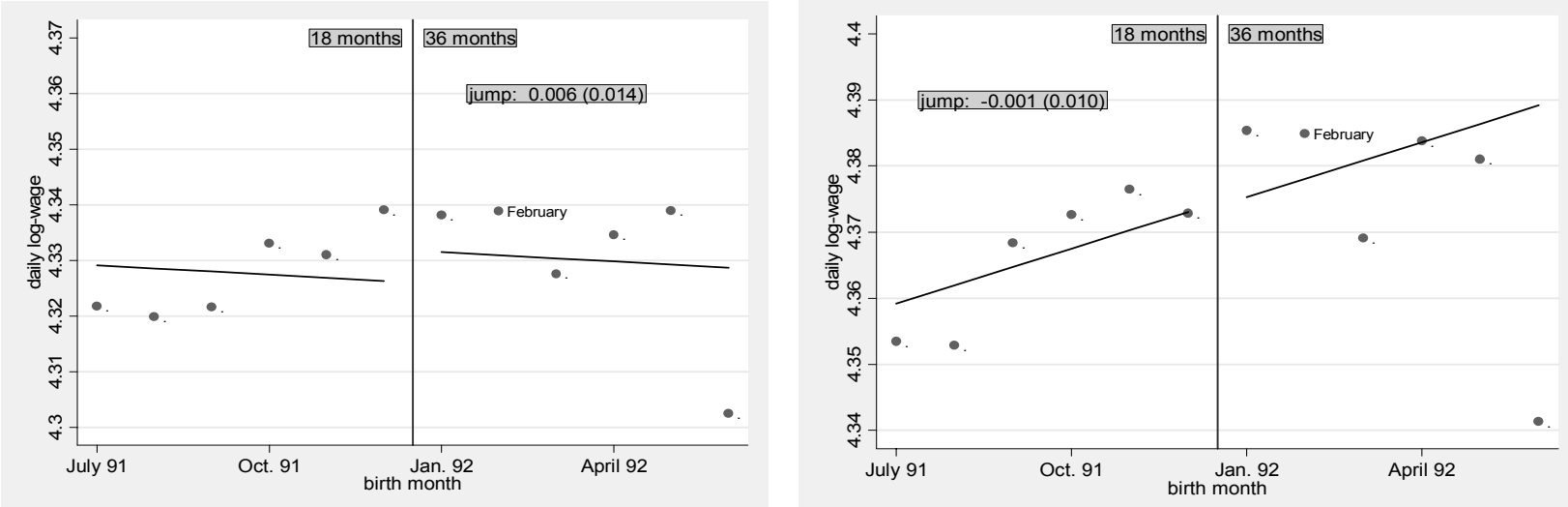

Note: The figure plots the average daily wage for women who are employed t months after childbirth by birth month, for women who give birth in a year in which there was no change in maternity leave legislation; see Figure 5 for the corresponding figure when a reform took place.. It also plots the predicted fraction, obtained from a linear regression that uses monthly data and controls for a linear time trend and a discontinuous jump when the law was changed ( $N=12)$. The figure in the box is the coefficient on the discontinuous jump. 